\title{
DERECHO PENAL E IMPUNIDAD EMPRESARIAL EN CHILE*
}

\author{
Criminal Law and corporate impunity in Chile
}

\begin{abstract}
Jaime Winter Etcheberry**
"The crimes of the lower class are handled by policemen, prosecutors, and judges, with penal sanctions in the form of fines, imprisonment, and death. The crimes of the upper class either result in no official action at all, or result in suits for damages in civil courts, or are handled by inspectors, and by administrative boards or commissions, with penal sanctions in the form of warnings, orders to cease and desist, occasionally the loss of a license, and only in extreme cases by fines or prison sentences."
\end{abstract}

Edwin Sutherland, White Collar Criminality

\begin{abstract}
Resumen: El presente trabajo busca mostrar en qué medida la exigencia social por más sanción de los delitos empresariales refleja carencias del sistema penal chileno y cómo esas carencias obedecen a una clara intención del legislador en mantenerlas. A la vez, se observa cómo reacciona el Ministerio Público ante esta exigencia pública, utilizando las herramientas que tiene a la mano, recurriendo a tipos penales secundarios e investigando por hechos no centrales al problema original, sin obtener buenos resultados y muchas veces sobreutilizando la prisión preventiva. Para esto, se revisan los casos de la colusión de las farmacias, sobre la impunidad penal de los atentados a la libre competencia; de Celco y Freirina, sobre la ausencia de un Derecho penal medioambiental; la mina San José, sobre la ausencia de un Derecho penal laboral; ADN-Nutricomp, sobre la reacción de la jurisprudencia ante problemas dogmáticos propios de la actividad empresarial; Lan y D\&S-Falabella, sobre la impunidad en la práctica del uso de información privilegiada; lucro en las universidades, sobre la ausencia de una figura de administración desleal; así como referencias a los casos Inverlink, La Polar y al cohecho entre privados.
\end{abstract}

Palabras clave: delincuencia económica y empresarial - impunidad - Derecho penal libre competencia - Derecho penal medioambiental - Derecho penal laboral información privilegiada - administración desleal.

Abstract: This paper intents to demonstrate up to which point the social demand for more punishment for the corporate crime is a reflection of the Chilean criminal system's shortages and how those shortages are because of a clear intention of the legislator to

\footnotetext{
* Esta es la versión extendida de la ponencia presentada en el seminario "Derecho penal e impunidad empresarial en Chile" organizado por el Centro de Estudios de la Justicia de la Facultad de Derecho de la Universidad de Chile el día 4 de septiembre de 2013. Agradezco los comentarios de los académicos Juan Gumucio, Gonzalo Medina y Jorge Cabrera, así como los comentarios posteriores a la exposición que han sido recogidos en esta versión. Los errores que subsistan son, por supuesto, propios.

** Becario DAAD y estudiante de doctorado de la Justus-Liebig-Universität Gießen. Académico del Departamento de Ciencias Penales de la Facultad de Derecho de la Universidad de Chile. Correo electrónico:jaimewinter@gmail.com.
}

Este artículo fue recibido el 25 de septiembre de 2013, siendo aprobada su publicación con fecha 6 de enero de 2014. 
Winter - Derecho penal e impunidad empresarial en Chile

maintain them. At the same time, it will beshown how the Prosecutor's Office reacts to this public claim, using the tools that they have around, without showing good results and many times overusing the custody. In order to achieve this goal the following cases are going to be revised: the collusion of drugstores, in relation to the Criminal impunity of antitrust conducts; Celcoand Frerina, in relation to the lack of an environmental criminal Law; the San José mine, about the lack of labor criminal Law; ADN-Nutricomp, about the reactios of our courts to scientific problems of the corporate crime; Lan and D\&SFalabella, about the practical impunity on the insider trade; profit in the universities, about the absence of an unfaithful administration figure (administración desleal); and references to the case of Inverlink, La Polar and to the corruption in the private sector.

Keywords: economic and coporatecrime - impunity - Criminal Law - Antitrust environmental criminal law - labor criminal law - insider trade - unfaithful administration.

\section{Introducción}

Como nunca antes, situaciones relacionadas con actividades empresariales ${ }^{1}$ que se perciben como injustas o incorrectas han generado atención o -más bienindignación en la opinión pública chilena. ${ }^{2}$ Cuando estalló el caso La Polar, y a propósito del rol de los auditores en el asunto, el vicepresidente del Colegio de Contadores Auditores dijo que "[e]n este momento la profesión del auditor está en el mismo papel que el cura pedófilo". 3 Esto muestra la nueva visión sobre la actividad ilícita empresarial que se está asentando y cómo la opinión de Sutherland, de que el delincuente de cuello blanco se caracteriza por ser considerado como un buen ciudadano, ${ }^{4}$ se ha visto superada, al menos, por la opinión pública.

El asunto es relevante, porque las empresas se han convertido en uno de los actores más importantes de nuestra vida social. Parafraseando a Tombs, no sólo afectan sino que también infectan nuestras vidas. ${ }^{5}$

Una buena parte de esa indignación se debe a que existe una sensación de impunidad, al menos penal, ${ }^{6}$ respecto de los delitos cometidos por los

${ }^{1} \mathrm{El}$ ámbito de delitos de los que aquí se trata son primariamente aquellos que se vinculan con la actividad empresarial, sin importar cuál sea el bien jurídico involucrado. Solo secundariamente se hace referencia a aquellos delitos que tienen como bien jurídico protegido el patrimonio y que son aquellos con que se suele identificar el Derecho penal económico. Sobre el concepto de Derecho penal económico en distintos sentidos y la de crimen corporativo, vid. Wittig (2011), pp. 7-14.

${ }^{2}$ Es evidente que dicha indignación también se produce respecto de otros delitos. El mejor ejemplo son los delitos sexuales. La novedad, entonces, no es la indignación, un fenómeno propio de nuestros tiempos, sino que dicha indignación también se produzca respecto de los delitos empresariales.

${ }^{3}$ BOGOLASKY (2011).

4 Vid. SUTHERLAND (1940), pp. 7-9.

5 TOMBS (2008), p. 18.

${ }^{6} \mathrm{Si}$ bien un análisis que fuera completo requeriría hacer referencia a la regulación administrativa, que muchas veces incluye sanciones relevantes, esto excede lo pretendido por este trabajo, aunque 
"poderosos". En esta exposición se pretende mostrar que tal apreciación no es totalmente antojadiza y tiene algún sustento en la realidad. Así las cuatro tesis -complementarias- que se intentarán ilustrar son: (1) Las organizaciones y, por tanto, quienes actúan a través de ellas, tienen un tratamiento privilegiado por parte de nuestro sistema penal -desde la legislación hasta la aplicación del Derecho-; (2) que dicho tratamiento privilegiado no se enmarca en una desidia general del legislador en la actualización del Derecho penal, sino que se ha optado por este tratamiento privilegiado; (3) que los órganos de persecución penal intentan enfrentar esto con las herramientas que tienen a mano, generando a veces distorsiones sobre el rol del sistema penal y falsas expectativas sobre sus resultados y; (4) que en algunos temas, por el contrario, el órgano persecutor ha optado por no valorar como especialmente graves los delitos en materia empresarial. Se aclara desde ya, que esto no implica asumir una tesis del "complot", sino que parece haber una consideración de la empresa como un ámbito no delictivo. Algo así como que la empresa "blanquea" las conductas que se cometen a través de ella.

Para ilustrar (más que para probar ${ }^{8}$ ) las tesis ofrecidas se hará referencia a algunos de los casos más polémicos -con una inclinación a la extensión más que a la profundidad- que se han producido en el último tiempo en nuestro país y que han involucrado organizaciones complejas; y se intentará explicar por qué se ha resuelto cómo se ha resuelto y qué problemas subyacen a ello. Dado que muchos de estos hechos no tuvieron una sentencia penal o no la tienen todavía, se asumirán las notas de prensa como correctas. Por último, es necesario hacer la salvedad que el análisis se centra en los casos en que existe como premisa una exposición pública del asunto, por lo que en aquellos en que no la hay, las reacciones, al menos en lo que se refiere a la reacción del Ministerio Público, tenderán a ser distintas y no están aquí cubiertas.

\section{Libre competencia y caso colusión de las farmacias}

Tal vez el caso más llamativo en este ámbito sea el de colusión de las farmacias. Según se ha sabido, posiblemente sintiéndose atrapados en virtud de una investigación de la Fiscalía Nacional Económica (en adelante FNE) iniciada el año 2008, Farmacias Ahumada opta por la delación compensada, reconociendo un acuerdo de precios con las otras dos grandes cadenas de farmacias: Cruz Verde y

\footnotetext{
se actúa bajo el presupuesto de que la mera sanción administrativa es insuficiente, como se hará referencia en (6).

${ }^{7} \mathrm{El}$ análisis original de Sutherland, si bien hacía referencia a los delitos cometidos por empresa, su punto central era respecto de la diferencia entre la criminalidad de una clase social y de otra. Tal enfoque ha perdido importancia en el análisis tanto dogmático penal como criminológico, pero parece ser algo que igual subyace a la indignación con este tipo de delitos. Vid. SUTHERLAND (1940), (nota 4), passim.

${ }^{8}$ La distinción entre ilustrar y probar fue usada por Sutherland en 1940 respecto de la criminalidad económica. En su caso, la tesis a probar era, más bien, que sí existía delincuencia en la clase alta. SUTHERLAND (1940), (nota 4) p. 3.
} 
Winter - Derecho penal e impunidad empresarial en Chile

Salcobrand. Según el requerimiento de la FNE cada Farmacia habría ganado entre 10 y 20 millones de dólares en virtud de su actuar concertado. ${ }^{9}$ Como base del acuerdo con la FNE, FASA debió pagar 1 millón de dólares, mientras que las otras farmacias, condenadas por el Tribunal de Libre Competencia (en adelante TDLC), debieron pagar multas ascendentes a 19 millones de dólares. ${ }^{10}$

Siendo un ámbito que tocaba de cerca a la mayoría de las personas, se produjo una importante indignación dentro de la población e incluso se llamó a boicotear a las farmacias, ${ }^{11}$ lo que no tuvo demasiado efecto práctico. ${ }^{12} \mathrm{Se}$ presentaron demandas colectivas contra las farmacias y FASA ofreció una compensación de alrededor de 4 millones de dólares a sus clientes, que fue considerada miserable. ${ }^{13}$

En materia penal se produce algo interesante: se inicia una investigación, principalmente debido a la presión pública. Para quienes conocen el medio, si bien no es sorpresivo que se iniciara la investigación, sí había escepticismo de que se fuera a lograr algo con la actividad del Ministerio Público. Se consideraba que, si bien hoy la Fiscalía se iba a ver como diligente al iniciar una potente investigación, era inevitable el escándalo cuando no se lograra nada.

Y ¿por qué se sospechaba que no se iba a lograr nada? Porque las conductas que atentan contra la libre competencia, entre ellas la colusión, no son delitos en nuestro país. Tanto es así, que cuando se presentan las denuncias y querellas por este tema y se pide un fiscal con dedicación exclusiva, el Fiscal Nacional habría señalado que "creemos que es un problema jurídico más que de investigación[...]", es decir, que más allá de la prueba de los hechos, no tenían claro si había delito o no y, de hecho, dice que hay fiscales con dedicación preferente y que se encargaron estudios para determinar qué delito habría e incluso reconoce la posibilidad de un vacío legal y que si es así lo informarían al parlamento. ${ }^{14}$ Ante esta situación, la Fiscalía hurga entre la normativa nacional y da con un tipo penal arcaico -el artículo 285 del Código Penal (en adelante CP)-, ${ }^{15}$ ya

\footnotetext{
9 Tabla $\mathrm{N}^{\circ}$ 7, p. 38 del Requerimiento en contra de Farmacias Ahumada S.A., Cruz Verde S.A. y Salcobrand S.A. presentado por la FNE ante el TDLC, disponible en http://www.tdlc.cl/DocumentosMultiples/Requerimiento FNE..pdf (consultado el 28.08.2013). 10 SCS 31.01.2012 causa rol $\mathrm{N}^{\circ}$ 2578-2012, disponible en http://www.tdlc.cl/Portal.Base/Web/VerContenido.aspx?GUID=\&ID=3015 (consultado el 28.08.2013).

11 DONOSO (2009).

${ }^{12}$ LA NACIÓN (2009a).

13 Así lo habría declarado Stefan Larenas, presidente de la Organización de Consumidores y Usuarios de Chile, ODECU. Vid. EL CIUDADANO: "Farmacias Ahumada 'compensará' a clientes", El ciudadano, 16.04.2009.

${ }^{14}$ LA NACIÓN (2009b).

15 Art. 285 CP: Los que por medios fraudulentos consiguieren alterar el precio natural del trabajo, de los géneros o mercaderías, acciones, rentas públicas o privadas o de cualesquiera otras cosas que fueren objetos de contratación, sufrirán las penas de reclusión menor en sus grados mínimo a medio y multa de seis a diez unidades tributarias mensuales.
} 
presente en el CP desde su promulgación 1874 y que ha sufrido mínimas variaciones, por tanto, proveniente de una época en que la libre competencia como la conocemos hoy no era realmente un tema. ${ }^{16}$ Este no es el espacio para discutir si este tipo es aplicable al caso, pero existe una discusión dogmática al respecto muy bien representada en el intercambio entre los académicos Héctor Hernández ${ }^{17}$ y Jean Pierre Matus. ${ }^{18}$ Lo que sí es importante recalcar es que el Ministerio Público está actuando en un ámbito de incertidumbre en este tema. Un riesgo bastante alto en cualquier causa penal.

Por otro lado, la carpeta de investigación llevada por el Ministerio Público es prácticamente inabarcable: miles de páginas de documentos, declaraciones e informes. Una investigación dura desde el punto de vista de la cantidad de elementos de juicio y de la complejidad de los mismos. Unos costos altísimos para el ente persecutor -y por tanto, para el país- considerando la incertidumbre de si podemos estimar los hechos como delito. Esta es, lamentablemente, la tónica en muchos delitos empresariales.

Por eso, el acuerdo al que se llegó de suspender condicionalmente el procedimiento -las vilipendiadas clases de ética empresarial ${ }^{19}{ }^{19}$ parecía no ser una solución inconveniente para las partes desde el punto de vista de las posibilidades reales que daba el sistema: ir a un juicio promete, casi indudablemente, un fracaso para todos los intervinientes: las penas necesariamente bajas o la posibilidad de absolución -que el tribunal considerara que no es delito coludirse- son un riesgo alto para el Ministerio Público después de un juicio oral que seguramente deberá durar meses y con alta exposición mediática; y para los imputados la exposición pública durante ese juicio implica un costo emocional y de imagen sumamente alto, siendo todos importantes ejecutivos de las empresas. ${ }^{20}$ Esto, sin perjuicio de que desde el punto de vista de la pena arriesgada, son casi más gravosas las clases de ética. ${ }^{21}$

\footnotetext{
${ }^{16}$ Su surgimiento en EE.UU. puede situarse a fines del siglo XIX. Vid. ERNST (1990), pp. 881 y ss.; MAY (1987), passim. En el caso chileno, solo en los años cincuenta puede hablarse realmente de una preocupación por el tema, desde la llegada de la misión Klein-Saks, cuyas propuestas se convirtieron en la Ley $\mathrm{N}^{\circ} 13.305$ Antimonopolios inspirada en la legislación antitrust de EE.UU. Vid. BERNEDO (2013), pp. 29, 34-46.

${ }^{17}$ HERNÁNDEZ (2012), pp. 147- 167.

${ }^{18}$ Matus (2012), pp. 318-356; y, el mismo (2013), pp. 314 a 362.

${ }^{19}$ Detalles de la suspensión condicional, que también incluía el pago de dinero a instituciones de beneficencia, en Vivanco (2013).

${ }^{20}$ Es llamativo que todos quienes fueron acusados en el caso detentaban altos cargos dentro de las farmacias vid. El listado con cargos en 24HORAS.CL (2012). Esto permite pensar en si en Chile existe una imputación "Top-Down” como se advierte en Alemania. Sobre el punto, SCHÜNEMANN (2002), p. 10.

${ }^{21}$ Unas "clases" serias de ética pueden redundar en alguna medida en fomentar la prevención de ilícito en las empresas, un tema fundamental desde la entrada en vigencia de la Ley de Responsabilidad de las Personas Jurídicas. La ley $\mathrm{N}^{\circ} 20.393$ que establece la dicha responsabilidad por determinados delitos establece en su artículo $3^{\circ}$ que la existencia modelo adecuado de prevención del delito podrá evitar que se haga responsable penalmente a la empresa.
} 
Tampoco es extraño, en todo caso, que posteriormente la Iltma. Corte de Apelaciones de Santiago haya dejado sin efecto ese acuerdo, aduciendo que no se cumplía con los requisitos de procedencia, por ser la pena probable más alta que tres años, ${ }^{22}$ obligando al Ministerio Público a llevar adelante un juicio oral que puede durar más de un mes. Algo similar pasó en el caso ADN-Nutricomp donde lo que se impidió fue un juicio abreviado. ${ }^{23} \mathrm{Si}$ bien las resoluciones rechazando los acuerdos, en ambos casos, están debidamente fundamentadas, ${ }^{24}$ cabe la duda de en qué medida elementos como la exposición pública del asunto han sido relevantes. En ese sentido, llama la atención el fundamento particular del voto de mayoría del ministro Zepeda que señala:

" $2{ }^{\circ}$ Que, para tal fin [la determinación de la gravedad del delito para establecer la procedencia de la suspensión condicional], la gravedad del delito en este caso no solo está determinada por la sanción penal de éste como criterio de valorización, pues, la suspensión condicional del procedimiento constituye una excepción al principio de legalidad procesal penal que obliga al Ministerio Público por regla general a promover y proseguir la acción penal pública, y, por lo tanto, por tal circunstancia, también son antecedentes a considerar, para determinar la cuantificación y gravedad del delito imputado, un juicio vinculado al análisis de los medios empleados para ejecutar las acciones imputadas, la peligrosidad de éstas y la extensión o magnitud efectiva de las lesiones a los bienes jurídicos resguardados en la norma penal tipo, ocasionadas precisamente con tales conductas; puesto que, no resulta admisible, conforme al principio de proporcionalidad mínima, de igualdad y de culpabilidad, que determinados sujetos se beneficien con la suspensión condicional del procedimiento penal, dirigida a hacer una excepción al principio de legalidad de promover y perseguir la persecución penal, desde las perspectivas antes indicadas, respecto de un delito que, como el de la especie, conforme a los hechos provisional pero categóricamente establecidos en la acusación, no es de poca o mediana gravedad, por cuanto, habría provocado graves y efectivas lesiones al bien jurídico resguardado por la figura penal, según fácilmente puede leerse y entenderse en la expresión de

\footnotetext{
22 SCA de Santiago, de 30.08.2013, rol N 1953-2013.

23 Vid. PODERJUdiCIAL.CL (2009).

${ }^{24}$ En el caso de la sentencia de la Iltma. Corte de Apelaciones de Santiago en la investigación sobre las farmacias, la Corte considera fundamental que es probable que se acredite una reiteración de delitos, es decir, un concurso real, lo que permitiría aumentar la pena en uno o dos grados y el hecho de que se reconociera la atenuante de colaboración sustancial para efectos del cálculo, lo que no sería procedente, como lo es en el caso de aceptarse un juicio abreviado. Vid. SCA de Santiago, de 30.08.2013, rol $\mathrm{N}^{\circ} 1953-2013$, considerandos $12^{\circ}$ y $13^{\circ}$.
} 
fundamentos de la acusación del Ministerio Público y que esta sentencia de segunda instancia transcribe en su considerando". ${ }^{25}$

Si bien la extensión del mal causado es un elemento a considerar para la determinación de la pena, ${ }^{26}$ es claro que la referencia que hace el ministro es a una gravedad ajena a los elementos mismos a considerar para la determinación de la pena, algo que indudablemente excede las facultades que el tribunal tiene al momento de decidir sobre la procedencia de la suspensión condicional.

Es posible todavía agregar un elemento adicional. Uno pudiera pensar que la falta de sanciones penales a la infracción de normas sobre libre competencia puede ser producto de un retraso del legislador en la materia. Las leyes son a veces más lentas que la realidad social y el legislador no se hace cargo de las nuevas realidades. Sin embargo, ese no ha sido el caso en materia de libre competencia. Por una parte, el legislador creó una institucionalidad moderna y eficiente para la persecución de estos asuntos como son actualmente la FNE y el TDLC. Simplemente consideró que esto no debía ser un problema penal. Pero más todavía: El DL $\mathrm{N}^{\circ} 211$ de diciembre de 1973, que es la llamada Ley Antimonopolios, en su versión original contenía un delito en su artículo $1^{\circ}$ donde se castigaban al que "ejecute o celebre, individual o colectivamente, cualquier hecho, acto o convención que tienda a impedir la libre competencia dentro del país en las actividades económicas, tanto en las de carácter interno como en las relativas al comercio exterior". Cabe destacar, además, que las penas se aumentaban en un grado "[...] cuando el delito incida en artículos o servicios esenciales tales como los correspondientes a alimentación, vestuario, vivienda, medicina o salud". Precisamente estos últimos - medicina y salud- son el caso de la colusión de las farmacias. Sin perjuicio de que habrían entrado a jugar otros factores, ${ }^{27}$ en abstracto, esta colusión habría estado amenazada con una pena de hasta diez años. Y la sanción penal a los atentados a la libre competencia no era una novedad que el DL $N^{\circ} 211$ introducía en nuestra legislación: ya el artículo 173 de la Ley $\mathrm{N}^{\circ} 13.305$, de 1959 , sancionaba los atentados contra la libre competencia. ${ }^{28}$

${ }^{25}$ SCA de Santiago, de 30.08.2013, rol No 1953-2013, fundamento particular del voto de mayoría, $\mathrm{N}^{\circ} 2$.

26 Art. 69 CP: Dentro de los límites de cada grado el tribunal determinará la cuantía de la pena en atención al número y entidad de las circunstancias atenuantes y agravantes y a la mayor o menor extensión del mal producido por el delito.

${ }^{27}$ Solo por hacer referencia a algunos de esos factores: en primer lugar, la existencia de la atenuante de irreprochable conducta anterior y, por otro, la tendencia de los tribunales a aplicar las penas en su grado mínimo.

${ }^{28}$ De especial interés es el inciso final que introduce como pena accesoria la disolución de la persona jurídica:

"Art. 173: Todo acto o convención que tienda a impedir la libre competencia dentro del país, sea mediante convenios de fijación de precios o repartos de cuotas de producción, transporte o de distribución, o de zonas de mercado; sea mediante acuerdos, negociaciones o asociaciones para obtener reducciones o paralizaciones de producción; sea mediante la distribución exclusiva, hecha por una sola persona o sociedad, de varios productores del mismo artículo específico, o por medio de cualquier otro arbitrio que tenga por finalidad eliminar la libre competencia, será penado con 
En cualquier caso, puede ser que la norma del DL $\mathrm{N}^{\circ} 211$ haya sido excesiva desde el punto de la culpabilidad y la proporcionalidad de la pena ${ }^{29}$ y pareciera ser un tipo penal abierto, lo que la hace criticable y requería de alguna modificación. De hecho, en treinta años de vigencia, la disposición nunca fue aplicada, entre otras razones, porque requería que el Fiscal Nacional Económico hiciera una denuncia o presentara una querella. ${ }^{30}$ Ahora, si bien el tipo requería cambios, se fue mucho más allá y el año 2003, cuando se crea el TDLC, ${ }^{31}$ se revierte la valoración que el legislador tuvo por más de cuarenta años y se decide que algo que se consideraba un asunto penal, pase a ser meramente administrativo.

Para recapitular, se observan aquí varios elementos que se dan en otros delitos empresariales: (1) No existen tipos penales para castigar las conductas. (2) La no existencia de estos delitos es una decisión consciente del legislador: en este caso derechamente se eliminaron los tipos penales. (3) El Ministerio Público inicia investigaciones por delitos análogos, con poca viabilidad, realizando costosas y largas investigaciones. (4) Esto termina con una solución procesal no muy intensa generando la sensación de impunidad de los partícipes (si bien con la revocación de la Corte de la suspensión condicional esto queda aún por ser acreditado).

\section{Delitos medioambientales: Celco y Freirina}

El año 2004 se produjo lo que se llamó un desastre ecológico por la muerte de cisnes de cuello negro en el Santuario de la Naturaleza Carlos Andwanter. En teoría, dichas muertes habrían sido causadas por una planta de Celulosa Arauco y Constitución (en adelante Celco). Esto se acreditó con un aparentemente lapidario informe de la Universidad Austral de Chile. ${ }^{32}$ El proceso judicial -no penalincluyó el cierre de la planta y la posterior revocación de esta decisión y

presidio menor en cualquiera de sus grados y con multa de uno por ciento al diez por ciento del capital en giro de los autores.

Los cómplices o encubridores serán penados con la multa señalada en el inciso anterior.

En el caso de personas jurídicas, si se tratare de reincidencia, además de la multa señalada en el inciso primero y de la responsabilidad penal que sea imputable a sus representantes, podrá el Tribunal aplicar, como pena accesoria la cancelación de la personalidad jurídica, la revocación de la autorización de existencia si se tratare de una sociedad anónima o de una agencia de sociedad anónima extranjera, o la disolución anticipada en los demás casos. La sentencia que aplique estas penas, tratándose de una sociedad anónima o comercial o de una agencia de sociedad anónima extranjera deberá ser inscrita en el Registro de Comercio respectivo y publicada en el 'Diario Oficial"'.

${ }^{29}$ En ese sentido, Hernández considera que vulneraría los principios del Derecho penal, aunque no aclara qué principios. HERNÁNDEZ (2005b), p. 126.

${ }^{30}$ Ibidem.

${ }^{31}$ Ley $\mathrm{N}^{\circ} 19.911$, de 14 de noviembre de 2003.

32 Dirección Regional Conama Xa Región de los lagos y Universidad Austral de CHILE (2005). 
acusaciones variadas, en especial la referida en un informe falso al que hizo referencia -según ellos erróneamente- la defensa de la planta. ${ }^{33}$

Paralelamente se inició una investigación penal. La causa terminó con la decisión de la fiscalía de no perseverar en octubre de $2010,{ }^{34}$ es decir, el Ministerio Público consideró que no había antecedentes suficientes para acusar.

Ante esto, los académicos José Muñoz Lorente y José Ángel Fernández Cruz reaccionaron con un duro artículo señalando que había antecedentes suficientes para llevar adelante el caso. ${ }^{35}$ Para realizar la imputación los autores sostienen que la conducta se subsume en dos tipos penales. Por un lado el artículo 291 del CP que sanciona a "[l]os que propagaren indebidamente organismos, productos, elementos o agentes químicos, virales, bacteriológicos, radiactivos, o de cualquier otro orden que por su naturaleza sean susceptibles de poner en peligro la salud animal o vegetal, o el abastecimiento de la población [...]". Parece servir para la situación, pero tiene el problema, por ejemplo, de no tener una hipótesis culposa. Siendo el dolo algo difícil de probar en los delitos medioambientales, las hipótesis culposas suelen ser algo común en la tipificación de esta clase de ilícitos penales. ${ }^{36}$ El otro tipo en que se subsumiría la conducta ${ }^{37}$ sería el del artículo 136 de la Ley $N^{\circ} 18.892$ General de Pesca y Acuicultura que sanciona la introducción en cuerpos de agua de productos que causen daños a los recursos hidrobiológicos. ${ }^{38}$ Si bien aquí sí se sanciona la comisión imprudente, la pena es apenas de multa. Es interesante, por lo demás, que se haga referencia a un tipo penal que no se vincula con la salud animal, siendo que lo central del caso es la muerte de los cisnes.

Por supuesto, el Derecho penal medioambiental muestra los típicos problemas del Derecho penal económico: es difícil probar la relación de causalidad entre la conducta y el daño y es difícil determinar a quién -dentro de la jerarquía de la organización- debe imputársele el hecho.

\footnotetext{
${ }^{33}$ Ver cronología del caso en Terra (2005).

34 MuÑoz, José y FERNÁndEZ, José Ángel (2010), p. 413.

${ }^{35}$ Ibidem, passim.

36 Así, el artículo 331 del CP Español sanciona las hipótesis de culpa grave de los delitos contra los recursos naturales y el medioambiente (arts. 325-330). El StGB tiene hipótesis culposas en cada uno de los delitos contra el Medioambiente (párrafos 324 y ss.).

${ }_{37}$ MuÑoz, José y FERnÁndEZ, José Ángel (2010) (nota 34), p. 445.

38 "El que introdujere o mandare introducir en el mar, ríos, lagos o cualquier otro cuerpo de agua, agentes contaminantes químicos, biológicos o físicos que causen daño a los recursos hidrobiológicos, sin que previamente hayan sido neutralizados para evitar tales daños, serán sancionado con multa de 50 a 3.000 unidades tributarias mensuales. Si procediere con dolo, además de multa, la pena aplicar será la de presidio menor en su grado mínimo.

Si el responsable ejecuta medidas destinadas a reparar el daño causado y con ello se recupera el medio ambiente, el tribunal rebajará la multa en un cincuenta por ciento, sin perjuicios de las indemnizaciones que correspondan".
} 
Winter - Derecho penal e impunidad empresarial en Chile

Junto con lo anterior, otro problema central en materia de delitos medioambientales es que existe una abundante cantidad de normas dispersas en el $\mathrm{CP}$ y leyes especiales, las que solo tangencialmente se refieren a problemas del medioambiente y que de manera central se refieren a otros asuntos, como, por ejemplo, la llamada salud pública. ${ }^{39}$ Así, a pesar de existir muchas normas aplicables a materias medioambientales, quedan importantes vacíos y la totalidad de los -no demasiados- autores que han investigado sobre el Derecho penal medioambiental han propuesto la consagración de estos delitos de manera ordenada y sistemática, ${ }^{40}$ como sucede en otros ordenamientos. ${ }^{41}$

Una discusión sobre el establecimiento de sanciones penales podría servir para hacer algunas definiciones básicas: El 2012 una planta de cerdos en la localidad de Freirina generó intensos malos olores, lo cual provocó un verdadero levantamiento de la población. ${ }^{42}$ Posteriormente, durante la investigación penal, la fiscalía habría descubierto un mal manejo de las aguas, lo que implicaría un peligro para la salud humana. ${ }^{43}$ Es probable que la investigación penal se centre en este segundo asunto. Tal como se verá para el proceso por el lucro en las universidades, ${ }^{44}$ la fiscalía también ha tenido suerte y ha encontrado un delito distinto a aquel por el que se inició la investigación para lograr calmar el clamor popular. Sin embargo, es posible que lo central del asunto -en este caso la generación de malos olores- quede impune. Un debate sobre si los malos olores que impiden un desarrollo normal de la vida humana debe ser algo punible si se derivan de inadecuados manejos industriales parece ser necesario, considerando que es la razón por la que se inician una buena parte de los conflictos medioambientales en Chile. ${ }^{45}$ En el Derecho comparado no es normal encontrar

\footnotetext{
${ }^{39}$ Vid., por ejemplo, MATus (2004), pp. 205 y 206.

${ }^{40}$ Así, Ibídem; las conclusiones de dicho trabajo fueron hechas suyas por la Comisión Foro Penal que realizó el anteproyecto de Código Penal de 2005, vid. MATUS (2008), pp. [304-324] 313 y ss.; también vid. MuÑOZ y FERNÁNDEZ (2010) (nota 34) pp, 410 y 411; HEFENDEHL (2008), pp. 5 y 6; Bascuñán manifiesta derechamente su extrañeza ante el hecho que la Ley $\mathrm{N}^{\circ} 19.300$ sobre Bases Generales del Medio Ambiente de 1994 no hubiera incluido un Derecho penal del medioambiente, BASCUÑÁN (2008), p. 5; sin hacerse cargo de la necesidad de criminalizar los atentados contra el medioambiente, pero sí criticando la situación legislativa actual en Chile, OvALLE (2004), p. [105113] 112; aunque pareciera en contra Ossandón, si bien en principio critica al Derecho penal del Medio Ambiente en términos generales -y sin referirse derechamente a la ley chilena- termina por reconocer que el Derecho penal podría cumplir una función en la sanción de los atentados más graves (OSSANDÓN (2003), p. [379-394] 394).

41 Por ejemplo, los párrafos 324 a 330d del StGB alemán y los artículos 325 a 331 del CP español. En general, sobre la regulación en el mundo continental, vid. MATUS (2004) (nota 39), pp. 53-128. En la misma obra, vid. pp. 171 a 204 en referencia al mundo anglosajón.

42 Vid. CAMPOS (2012).

43 Desormenaux y RAMíreZ (2012).

${ }^{44} \mathrm{Vid}$, infra sección 7.

${ }^{45}$ Un ejemplo es el caso de la planta de Aguas Andinas La Farfana, donde se condenó a la empresa a una millonaria indemnización por daño moral a favor de los vecinos de la planta. Vid. SCA de Santiago de 25.07.2013 en causa rol 3147 de 2010 y la sentencia de primera instancia del $5^{\circ}$ Juzgado Civil de Santiago de fecha 30.03.2012 en causa rol 3684-2001. Ambas sentencias, además de un
} 
provisiones claras en ese sentido, pero no sería impensable implementar un tipo que sancionara la emanación de malos olores de manera permanente con infracción de normas reglamentarias que hicieran imposible el desarrollo de la vida humana en ese lugar.

Ahora bien, nuevamente, uno podría pensar que la falta de legislación penal en materia medioambiental es porque el legislador, en general, no se ha preocupado de los temas medioambientales. Una mera falta de modernización del sistema. Sin embargo, es llamativo que el 2010 se publicó la Ley $\mathrm{N}^{\circ} 20.417$ que crea una nueva institucionalidad medioambiental. En dicha ley no existe un solo delito medioambiental. Es evidente que el legislador no consideró que el medioambiente fuera un ámbito digno de ser protegido de manera penal.

\section{Derecho Penal Laboral y la Mina San José}

El accidente de la mina San José que dejó a treinta y tres mineros atrapados bajo tierra y el posterior rescate fue uno de los eventos más importantes de los últimos años en Chile, implicando una enorme importancia política para el gobierno en ejercicio. La transmisión en vivo del rescate se vio en todo el mundo e incluso catapultó al en ese entonces ministro de minería a una -fallida- carrera presidencial.

Al parecer, habría antecedentes de que el accidente se produjo porque los encargados de la mina no habrían tomado las medidas de seguridad necesarias. Existirían, al respecto, denuncias ante los entes fiscalizadores, que estos no habrían atendido de manera suficiente. ${ }^{46}$ Tanto es así que la investigación penal se siguió también contra autoridades del Servicio Nacional de Geología y Minería (Sernageomin). ${ }^{47}$

Sorprendió a la opinión pública que en agosto de 2013 la Fiscalía de Atacama decidió no perseverar en la investigación, esto es, decidió que no hay antecedentes suficientes para realizar una acusación. ${ }^{48}$ Nuevamente esto causó frustración en el público y en los involucrados, e incluso uno de los mineros rescatados declaró que es como si los devolvieran a la mina. ${ }^{49}$

Una vez más, esta decisión no es sorprendente. No murió nadie y ninguno de los mineros sufrió lesiones, por lo que esos delitos culposos no se podrían

resumen de las mismas y referencia al caso similar de Villa Alto Jahuel de Pudahuel, en PODERJUDICIAL.CL (2013).

46 Palacios (2010).

47 ARgandoña (2010).

48 Abramovich (20113).

49 Ibidem. 
Winter - Derecho penal e impunidad empresarial en Chile

aplicar. ${ }^{50}$ De hecho, a lo que más se parecería el hecho es a un secuestro negligente. Algo que, por supuesto, no es delito en nuestra legislación.

El asunto es que si uno revisa la legislación comparada existe un ámbito especial de delitos de los empleadores contra los trabajadores. Así, por ejemplo, el Código Penal Español tiene un Título XV "De los delitos contra los derechos de los trabajadores", dentro de los cuales, el artículo 317 señala que:

Los que con infracción de las normas de prevención de riesgos laborales y estando legalmente obligados, no faciliten los medios necesarios para que los trabajadores desempeñen su actividad con las medidas de seguridad e higiene adecuadas, de forma que pongan así en peligro grave su vida, salud o integridad física, serán castigados con las penas de prisión de seis meses a tres años y multa de seis a doce meses.

Este delito también se castiga cuando sea realizado de manera culposa (artículo 318 del CP Español).

Algo que merece atención es que es posible en países como Alemania y España identificar un verdadero Derecho penal laboral, algo que en Chile no existe. Si bien hay algunos atisbos: existe la apropiación indebida de cotizaciones previsionales $^{51}$ - un tipo de poco uso en la práctica-, y se hace una referencia laboral a la trata de personas, ${ }^{52}$ las conductas más centrales del Derecho penal laboral son impunes. Comparándolo con el caso español, ahí se sancionan penalmente la imposición de condiciones laborales contrarias a derechos laborales incluidos en leyes, contratos colectivos o individuales (art. $311 \mathrm{~N}^{\circ} 1$ ), así como también se sancionan penalmente las prácticas antisindicales o contra el derecho a huelga (art. 315). Esto permite advertir que en Chile el legislador no ha considerado que el trabajo deba ser objeto de protección penal.

\footnotetext{
${ }^{50}$ La posición de garante del empleador estaría dada por el artículo 184 del Código del Trabajo que en su inciso primero señala que: "El empleador estará obligado a tomar todas las medidas necesarias para proteger eficazmente la vida y salud de los trabajadores, informando de los posibles riesgos y manteniendo las condiciones adecuadas de bigiene y seguridad en las faenas, como también los implementos necesarios para prevenir accidentes y enfermedades profesionales".

${ }^{51}$ Según el artículo 19 del DL N 3.500 y 13 de la Ley $N^{\circ} 17.322$, “se aplicarán las penas del artículo 467 del Código Penal al que en perjuicio del trabajador o de sus derechohabientes se apropiare o distrajere el dinero proveniente de las cotizaciones que se hubiere descontado de la remuneración del trabajador".

52 Artículo 411 quater del CP: El que mediante violencia, intimidación, coacción, engaño, abuso de poder, aprovechamiento de una situación de vulnerabilidad o de dependencia de la víctima, o la concesión o recepción de pagos u otros beneficios para obtener el consentimiento de una persona que tenga autoridad sobre otra capte, traslade, acoja o reciba personas para que sean objeto de alguna forma de explotación sexual, incluyendo la pornografía, trabajos o servicios forzados, servidumbre o esclavitud o prácticas análogas a ésta, o extracción de órganos, será castigado con la pena de reclusión mayor en sus grados mínimo a medio y multa de cincuenta a cien unidades tributarias mensuales.
} 


\section{El rol de la jurisprudencia y el caso ADN-Nutricomp}

Otro caso que causó revuelo en la opinión pública es el llamado ADN-Nutricomp, posiblemente el más importante de responsabilidad por el producto en la historia de Chile. ${ }^{53} \mathrm{~A}$ grandes rasgos, ADN-Nutricomp era un suplemento alimenticio para personas con deficiencia de potasio. Se sabe que el producto no tenía la cantidad de potasio que debía tener y que anunciaba; se sabe que muchas de las personas que lo consumieron presentaron una hipocaliemia, que, precisamente, es una baja de concentración de potasio en la sangre; se sabe que varias de esas personas debieron ser internadas en hospitales o que murieron. ${ }^{54}$ Sin embargo, a pesar de estar acreditados estos hechos, la Corte Suprema, tal como lo hizo el tribunal de instancia, descartan que exista un nexo de causalidad y, por lo tanto, el delito por el que se condena no es por causar la muerte -dolosa o culposamente- ${ }^{55}$ sino que por un delito de peligro contra la llamada salud pública. ${ }^{56}$

¿Basándose en qué decide esto? Tal vez lo único que se puede colegir de los cuatro casos analizados en el Considerando Segundo de la sentencia es que podían existir otras causas posibles. Respecto de la víctima MFG existían otras condiciones previas y, además, presentó hipocaliemias posteriormente. En cuanto a la víctima NVA, consideran suficientes la existencia de "otros factores". Sorprende la aseveración de que "Si bien sus otras alteraciones no se asocian habitualmente a la hipocaliemia, no puede asegurarse en este caso que no hubiera nada que pudiera haber influido en algo". Eso es literal. Sobre la víctima CC, si bien parecen considerar que no tienen elementos de juicio suficientes, llama la atención que consideren relevante documentos clínicos en que se sostiene que la hipocaliemia es de "causa no precisada". Evidentemente la labor de los médicos que la atendieron no es la de un perito forense. En cuanto a la víctima SG, también se le da relevancia a que consumía otros alimentos y otros fármacos.

Muchas veces en responsabilidad por el producto el problema es determinar la causalidad general: no se sabe cómo ha actuado el producto sobre la salud. Ese es el caso, por ejemplo, del famoso Lederspray o spray para cuero en

\footnotetext{
${ }^{53}$ Hernández señalaba el año 2006 que no había ningún gran proceso en la materia. Hasta el caso ADN esto no había variado. HERNÁNDEZ (2006), p. 8. Sobre esto mismo, ya se había hecho referencia en WINTER (2013), p. 346.

${ }^{54}$ Vid. SCS de 27.12.2012 en causal rol 6831-2012.

${ }^{55}$ Se aplicaría, en relación con el artículo 315 CP, el artículo 317 CP: Si la consecuencia de cualquiera de los delitos señalados en los cuatro articulos precedentes, se produjere la muerte o enfermedad grave de alguna persona, las penas corporales se elevarán en uno o dos grados, según la naturaleza y número de tales consecuencias, la multa podrá elevarse hasta el doble del máximo señalado en cada caso.

Si alguno de tales hechos punibles se cometiere por imprudencia temeraria o por mera negligencia con infracción de los reglamentos respectivos, las penas serán de presidio menor en su grado mínimo o multa de seis a veinte unidades tributarias mensuales.

56 Artículo 315 inc. $2^{\circ}$ del CP: El que efectuare otras adulteraciones en dichas sustancias destinadas al consumo público, de modo que sean peligrosas para la salud por su nocividad o por el menoscabo apreciable de sus propiedades alimenticias, y el que a sabiendas las vendiere o distribuyere, serán penados con presidio menor en su grado máximo y multa de seis a cincuenta unidades tributarias mensuales.
} 
Alemania, donde nunca se supo qué componente del producto producía los efectos negativos en el cuerpo humano. Aquí el problema no es ese, se sabe bien que las personas necesitaban potasio y que no recibieron el suficiente. El problema es que, dado que las personas están enfermas, se considera que pudo haber sido otra cosa la causa de la muerte o el daño a la salud, aunque sorprendentemente no existan verdaderos antecedentes de ello.

En otros países, para enfrentar este tipo de casos, la idea de que el resultado es una consecuencia regular del hecho, ha ido reemplazando a la noción de que es una consecuencia necesaria del hecho. ${ }^{57} \mathrm{Y}$ es razonable recurrir a una idea como esa, porque en base a la conditio sine qua non sin correcciones pareciera que simplemente no es posible perseguir investigaciones por medicamentos defectuosos.

Esto nos muestra que no siempre el problema es la legislación, sino que muchas veces también nuestras posiciones dogmáticas y jurisprudenciales se han quedado ancladas en épocas de menor complejidad.

\section{Información privilegiada, casos Lan y D\&S-Falabella}

En su conocido artículo de 2005, Hernández se refirió, entre las "normas temibles poco aplicables", al uso de información privilegiada. ${ }^{58} \mathrm{Al}$ respecto, cabe hacer preliminarmente un comentario sobre la relación entre el Derecho penal y el Derecho administrativo sancionador. $Y$ es que mucho se habla de que el administrativo sancionador es suficientemente intenso en estos asuntos, como en el caso de los atentados a la libre competencia o al medioambiente. No es posible hacer referencia a esa discusión aquí, pero valga recordar un hecho. El año 2007 el actual Presidente de la República Sebastián Piñera fue sancionado administrativamente por no abstenerse de hacer una compra teniendo información privilegiada en el llamado caso Lan. ${ }^{59}$ Cuando su contendor en la carrera presidencial sacó a relucir esto durante la campaña, el argumento que el actual Presidente de la República usó como defensa fue que -por supuesto- la infracción no era el uso de información privilegiada, sino que no cumplir con una abstención, agregando que una era una conducta penalmente relevante, y la otra constituía una "mera falta administrativa" ${ }^{60}$ En fin, sin pretender hacer aquí un análisis político, la diferencia entre el Derecho administrativo sancionador y el penal, puede ser la diferencia entre ser presidente de la república o ser considerado un delincuente.

\footnotetext{
${ }^{57}$ Por ejemplo, Roxin (2006), p. 67.

58 HERNÁNDEZ (2005b) (nota 29), pp. 126 y ss.

59 Resolución Exenta $N^{\circ} 306$ de la Superintendencia de Valores y Seguros de 06.07.2007, disponible en http://www.svs.cl/documentos/res/res 2007 306.pdf (consultado el 03.08.2013).

${ }^{60}$ LA NACIÓN (2009c).
} 
Curiosamente, hay varias normas que sancionan penalmente el uso de información privilegiada, sin embargo no suele haber casos en que se apliquen sanciones penales por uso de información privilegiada. ${ }^{61}$ Sí hay, por otro lado, sanciones administrativas que efectivamente se aplican. ${ }^{62}$ Es posible que las causas sean la deficiencia de las normas o la falta de interés de los órganos de persecución en ese tipo de delitos.

Respecto de la deficiencia de las normas, en el 2005 Hernández se quejaba de la técnica legislativa del art. 60 (literal e) de la Ley $\mathrm{N}^{\circ} 18.045$ de Mercado de Valores, porque para sancionar a los insiders primarios -es decir, directores, gerentes, administradores y ejecutivo principales, entre otros $-{ }^{63}$ se exige que usen deliberadamente la información privilegiada que poseen. ${ }^{64}$ Hernández aboga, en cambio, por un tipo que acreditándose que se tiene dicha información y que se hizo la compra sea suficiente para imponer la sanción penal. ${ }^{65} \mathrm{Si}$ se piensa, eso sería equivalente -con algunas salvedades- ${ }^{66}$ a sancionar penalmente la obligación de abstenerse que habría infringido el Presidente de la República Sebastián Piñera.

Esta necesidad de usar deliberadamente la información no sería la única barrera impuesta en el tipo subjetivo. Otros tipos penales sobre uso de información privilegiada exigen que el uso de la información privilegiada sea "con objeto de obtener un beneficio pecuniario o evitar una pérdida". Este tipo de barreras no se encuentran en otras legislaciones como la española ${ }^{68}$ o la alemana. ${ }^{69}$

\footnotetext{
${ }^{61}$ Como excepción, vid. Rosenblut (2011), pp. 185-209.

${ }^{6}$ Así, los casos Lan, Eurolatina y D\&S-Falabella, todos a los cuales alguna referencia se hace aquí.

${ }^{63}$ Artículo 166 de la Ley $\mathrm{N}^{\circ} 18.045$ de Mercado de Valores.

${ }^{64}$ HERNÁNDEZ (2005b) (nota 29), p. 128.

${ }^{65}$ Ibidem, pp. 128 y 129.
}

${ }^{66}$ El Presidente de la República Sebastián Piñera señaló que la adquisición estaba programada previamente a la obtención de la información privilegiada. Esto significa que no la habría usado realmente.

${ }^{67}$ Artículo 60, literales g y h de la Ley $\mathrm{N}^{\circ}$ 18.045: Sufrirán las penas de presidio menor en cualquiera de sus grados:

g) El que valiéndose de información privilegiada ejecute un acto, por sí o por intermedio de otras personas, con objeto de obtener un beneficio pecuniario o evitar una pérdida, tanto para sí como para terceros, mediante cualquier tipo de operaciones o transacciones con valores de oferta pública; h) El que revele información privilegiada, con objeto de obtener un beneficio pecuniario o evitar una pérdida, tanto para sí como para terceros, en operaciones o transacciones con valores de oferta pública

68 En España, el artículo 285 del CP exige que haya existido una ganancia efectiva de al menos 600.000 euros, lo cual no es un límite subjetivo, sino que objetivo, que tienen que ver con la relevancia de la conducta: 1. Quien de forma directa o por persona interpuesta usare de alguna información relevante para la cotización de cualquier clase de valores o instrumentos negociados en algún mercado organizado, oficial o reconocido, a la que haya tenido acceso reservado con ocasión del ejercicio de su actividad profesional o empresarial, o la suministrare obteniendo para sí o para un tercero un beneficio económico superior a 600.000 euros o causando un perjuicio de idéntica cantidad, será castigado con la pena de prisión de uno a cuatro años, multa del tanto al triplo del beneficio obtenido o favorecido e inhabilitación especial para el ejercicio de la profesión o actividad de dos a cinco años. 
Winter - Derecho penal e impunidad empresarial en Chile

Sin embargo, estas barreras no son particularmente infranqueables. Si se piensa, ¿no será acaso lo normal que las transacciones de la bolsa sean para obtener beneficios o evitar perjuicios? ${ }^{70}$

En ese sentido, las normas, si bien criticables en algunos sentidos, deberían poder ser aplicables a los casos más nucleares que se producen en la práctica. En efecto, siendo que las normas no difieren tanto de las que imponen sanciones administrativas, llama la atención lo que parece ser una cierta falta de interés del Ministerio Público de perseguir este tipo de hechos.

El caso del uso de información privilegiada en el contexto de la frustrada fusión entre las empresas D\&S y Falabella es uno de los pocos en que existió una investigación penal. ${ }^{71}$ En materia administrativa hay una sentencia confirmada por la Excma. Corte Suprema ${ }^{72}$ y varias multas impuestas por la Superintendencia de Valores y Seguros. ${ }^{73}$ En materia penal la investigación se formalizó respecto de varios de los involucrados, pero finalmente se optó por una suspensión

${ }^{69}$ En Alemania se regula en el parágrafo 38 de la Ley de Mercado de Valores (WpHG), donde de todos modos se exige que se utilice dicha información: Strafvorschriften

(1) Mit Freiheitsstrafe bis zu fünf Jahren oder mit Geldstrafe wird bestraft, wer

1. entgegen $\ 14$ Abs. 1 Nr. 1 ein Insiderpapier erwirbt oder veräußert oder

2. a) als Mitglied des Geschäftsführungs- oder Aufsichtsorgans oder als persönlich haftender Gesellschafter des Emittenten oder eines mit dem Emittenten verbundenen Unternehmens,

b) auf Grund seiner Beteiligung am Kapital des Emittenten oder eines mit dem Emittenten verbundenen Unternehmens,

c) auf Grund seines Berufs oder seiner Tätigkeit oder seiner Aufgabe bestimmungsgemäß oder

d) auf Grund der Vorbereitung oder Begehung einer Straftatüber eine Insiderinformation verfügt und unter Verwendung dieser Insiderinformation eine in $\ 39$ Abs. 2 Nr. 3 oder 4 bezeichnete vorsätzliche Handlung begeht.

(2) Ebenso wird bestraft, wer eine in $\int 39$ Abs. 1 Nr. 1 oder Nr. 2 oder Abs. 2 Nr. 11 bezeichnete vorsätzliche Handlung begeht und dadurch

1. auf den inländischen Börsen- oder Marktpreis eines Finanzinstruments, einer Ware im Sinne des $\int 2$ Abs. 2c, einer Emissionsberechtigung im Sinne des $\int 3$ Nummer 3 des TreibhausgasEmissionshandelsgesetzes oder eines ausländischen Zahlungsmittels im Sinne des $\$ 51$ des Börsengesetzes,

2. auf den Preis eines Finanzinstruments an einem organisierten Markt in einem anderen Mitgliedstaat der Europäischen Union oder in einem anderen Vertragsstaat des Abkommens über den Europäischen Wirtschaftsraum oder

3. auf den Preis einer Ware im Sinne des $₫ 2$ Abs. 2c, einer Emissionsberechtigung im Sinne des $₫ 3$ Nummer 3 des Treibhausgas-Emissionshandelsgesetzes oder eines ausländischen Zahlungsmittels im Sinne des $\int 51$ des Börsengesetzes an einem mit einer inländischen Börse vergleichbaren Markt in einem anderen Mitgliedstaat der Europäischen Union oder in einem anderen Vertragsstaat des Abkommens über den Europäischen Wirtschaftsraum

${ }^{70}$ Hernández considerada que en temas novedosos estos defectos legislativos pueden traducirse en una inhibición de los órganos de persecución. Hernández B. Héctor: "Perspectivas...” (nota 29), p. 130.

${ }^{71}$ Ver relación de hechos en el comunicado de prensa de la SVS: SVS, SVS hace pública sanción por uso de información privilegiada en compra de acciones e incumplimiento de deber de reserva, (17.07.2008), disponible en http://www.svs.cl/sitio/admin/Archivos/com 200803149-01.PDF (consultado el 13.09.2013).

72 SCS de 10.01.2013, rol 5048-2012.

${ }^{73}$ Vid. nota al pie 71. 
condicional del procedimiento, lo que implica que no hay reconocimiento de responsabilidad, sino que solo algunas condiciones, que consistieron en el pago de dinero a algunas beneficencias. ${ }^{74}$

Si bien nadie puede criticar el uso de una salida alternativa como la suspensión condicional como mecanismo general, es evidente que ella implica una opción y una declaración del Ministerio Público sobre este tipo de casos, considerando que no es el único en que se ha actuado así. ${ }^{75}$ Por ejemplo, las fiscalías tienen la política que sobre cierta cantidad de gramos de alcohol en la sangre no es posible que un manejo en estado de ebriedad termine por una salida alternativa y se debe ir a juicio. Que no haya una política similar en casos económicos de gran envergadura tiene, sin duda, un significado difícil de eludir. La destacada fiscal Ximena Chong -en ese entonces jefa de la unidad de Delitos Económicos de la Fiscalía Centro Norte-, advirtiendo que tenían un buen caso, justificó la salida alternativa en virtud de las bajas penas que hay para los delitos económicos. ${ }^{76} \mathrm{Si}$ semejante argumento es suficiente, es una pregunta que queda pendiente.

\section{El rol del Ministerio Público: caso lucro en las universidades}

Un asunto donde se ve con claridad el rol del Ministerio Público en los delitos económicos es el llamado caso del lucro en las universidades. Además, es posible utilizarlo para mostrar uno de los acusados vacíos en nuestra legislación. Aquí, lo que originalmente existió fue una denuncia contra universidades que -mediante distintas fórmulas- repartirían utilidades entre sus propietarios, siendo que se constituyen como entidades sin fines de lucro. ${ }^{77}$

La pregunta natural era, si bien no cabe duda de la ilegalidad de la repartición de utilidades utilizando contratos de arrendamiento y otras fórmulas, si esa ilegalidad podía ser subsumida en algún tipo penal. El propio fiscal de la causa ha dicho, derechamente, que "la sola conducta de lucro, es decir, que se obtengan utilidades a pesar de que están prohibidas por la ley, no está tipificado penalmente...". ${ }^{78}$

\footnotetext{
${ }^{74}$ Respecto de los primeros cinco imputados: Ferrando, K., Torres, C.: "Cinco imputados en caso D\&S-Falabella alcanzan acuerdo con fiscalía”, La Tercera, 08.02.11. Luego, respecto de dos más: VILLALOBOS (2011).

75 Muy parecido es también el caso de Francisco Montaner y Roberto Guzmán, que también terminó con una suspensión condicional del procedimiento. Vid. la sanción administrativa en resolución exenta $\mathrm{N}^{\circ} 414$ de la Superintendencia de Valores y Seguros (SVS) de fecha 13.07.2010, disponible en http://www.svs.cl/documentos/res/res 2010 414.pdf (consultado el 12.09.2013). Sobre el caso penal, vid. ELGUETA (2012).

${ }^{76}$ Vega (2013).

77 Referencia al inicio de la investigación en EL MOSTRADOR.CL (2013). Sobre cómo funcionaría el sistema para lucrar que utilizan, vid. TORRES, GUZMÁN y RIQUELME (2011).

78 Vid. MELO (2013).
} 
Posiblemente una figura que tendría sentido en este ámbito sería la de la administración desleal, cuya ausencia en nuestra legislación es uno de los vacíos permanentes que destaca Hernández. ${ }^{79}$ La idea de la administración desleal es que quien tiene la facultad de disposición sobre un patrimonio o de obligar jurídicamente a otros abusa de esa facultad; o quien tiene la obligación de velar por un patrimonio ajeno y perjudique ese patrimonio será sancionado por ese hecho. ${ }^{80}$ $\mathrm{Si}$ entendemos que contratos con sobreprecio - si el precio fuera considerado "adecuado" 81 no habría mucho que decir- para retirar fraudulentamente dinero de la universidad perjudican su patrimonio - entendiendo que la universidad es una entidad distinta de sus dueños-, estaríamos frente a un caso de administración desleal. En Chile, la hipótesis de la apropiación indebida ${ }^{82}$ no se puede aplicar, principalmente porque suscribir un contrato perjudicial es una forma de aumentar el pasivo, lo que no constituye una verdadera apropiación. ${ }^{83}$

¿Qué hace la fiscalía entonces ante este panorama? Debe buscar una alternativa. Ya hemos visto otros casos en que se opta utilizar tipos penales en cuyo núcleo no están precisamente las conductas investigadas. Así, la fiscalía está estudiando encuadrar estas conductas en los delitos de fraude al fisco o delitos tributarios y el fiscal de la causa derechamente ha dicho que "lo que estamos haciendo es investigar si existen otro tipo de conductas que puedan configurar delitos penales y a eso estamos avocados [sic]" ${ }^{84}$ Podríamos decir, además, que la fiscalía tuvo suerte. En efecto, se encontraron relaciones comerciales contractuales entre un miembro de la Comisión Nacional de Acreditación y algunas de las universidades que se sometían a la acreditación. ${ }^{85}$ El delito imputado es el de cohecho. Como se puede observar, si bien en cierta medida para la opinión pública el juicio sigue siendo sobre el lucro en las universidades - tal vez como símbolo de un modelo negativo-, el lucro es un asunto que dejó hace mucho tiempo de ser central en la investigación. Así el Ministerio Público debe buscar alternativas para satisfacer a la opinión pública.

\footnotetext{
79 HERNÁNDEZ (2005b), pp. 203 y ss.

80 \$ 266 del StGB (Código Penal Alemán): “Untreue.

(1) Wer die ihm durch Gesetz, behördlichen Auftrag oder Rechtsgeschäft eingeräumte Befugnis, über fremdes Vermögen zu verfügen oder einen anderen zu verpflichten, mißbraucht oder die ihm kraft Gesetzes, behördlichen Auftrags, Rechtsgeschäfts oder eines Treueverhältnisses obliegende Pflicht, fremde Vermögensinteressen wahrzunehmen, verletzt und dadurch dem, dessen Vermögensinteressen er zu betreuen hat, Nachteil zufügt, wird mit Freiheitsstrafe bis zu fünf Jahren oder mit Geldstrafe bestraft".

${ }^{81}$ Sobre las dificultades de hablar de precio de mercado, vid. WINTER y SANHUEZA (2013).

82 Art. 470 CP: "Las penas del artículo 467 se aplicarán también:

$1^{\circ} \mathrm{A}$ los que en perjuicio de otro se apropiaren o distrajeren dinero, efectos o cualquiera otra cosa mueble que hubieren recibido en depósito, comisión o administración, o por otro título que produzca obligación de entregarla o devolverla".

83 Vid. HERNÁNDEZ (2005b) (nota 79), p. 232.

${ }^{84}$ Vid. Melo (2013) (nota 78).

${ }^{85}$ Como ejemplo de uno de los casos, vid. LA TerCERA.CL (2012).
} 
Pero hay algo más interesante sobre el rol del Ministerio Público. Las penas de cohecho no son particularmente altas en nuestro sistema. ${ }^{86}$ El Ministerio Público, entonces, opta por formalizar la investigación por el delito de lavado de activos. No es posible hacerse cargo aquí del análisis al respecto, pero cabe considerar que una condena por lavado de activos es poco probable. Sin embargo, formalizar la investigación por dicho delito permite que la pena probable en abstracto y la gravedad del hecho sean mayores, lo que implica mayores probabilidades de obtener la prisión preventiva, lo cual efectivamente sucedió en la práctica. ${ }^{87}$

Es evidente que para conceder la prisión preventiva no se exige una actividad equivalente en estándar a la prueba para lograr una condena. En cierta medida esto se ha extrapolado al proceso de subsunción de la conducta en una figura específica. Así, la discusión de fondo, sobre si es efectivo o no que los hechos imputados configuran un delito específico también parece exigir un estándar menor. Es decir, se determina que la subsunción es plausible.

En la práctica y ante la alta probabilidad de obtener bajas condenas, la prisión preventiva se ha convertido en una suerte de pre-pena, una forma de obtener algún tipo de castigo en una situación que a la vista del público terminará con uno insuficiente. No solo el caso de las universidades es un ejemplo de esto, sino que también algo similar pasó en los procesos ADN y La Polar. ${ }^{88}$ Esto es algo que, como es evidente, contradice las finalidades declaradas de la prisión preventiva, que son la de garantizar los actos del proceso -o sea, evitar la fuga o la alteración o desaparición de prueba- o evitar un peligro para la sociedad o las víctimas. En ese sentido, suele suceder que respecto de los delitos empresariales, especialmente considerando que las penas de los delitos empresariales en Chile no son tan altas y que normalmente estos hechos son delitos ocupacionales - es decir, se producen en el ámbito de la actividad laboral del imputado-, pareciera que los fines de la prisión preventiva no están presentes. Al individuo no le conviene escaparse y, por otro lado, no representa un peligro para la sociedad una vez alejado de sus funciones. Que sea un peligro para la investigación (algo rara vez alegado como fundamento) es dudoso: normalmente a la altura de la formalización seguramente ya quemó todos los papeles que había que quemar, considerando que las investigaciones penales se inician en estos casos solo una vez que se ha hecho público el conflicto debido a una investigación administrativa.

\footnotetext{
${ }^{86} \mathrm{El}$ artículo 248 bis, figura central del cohecho cometido por funcionario público tiene una pena de reclusión menor en su grado medio, aplicable en virtud del artículo 250 del CP al privado que ofreciere o consintiere en dar al empleado público el beneficio económico propio del cohecho.

${ }^{87}$ SCA de Santiago, de 30.11.2012, causa rol 3293-2012.

${ }^{88}$ En el caso La Polar, si bien se acusó a algunos de los involucrados de lavado de activos, la jueza de garantía negó que estuviera acreditado y, según informaciones de prensa, se habría referido a la "extensión del mal causado y a que serían un peligro para la sociedad". EMOL (2011).
} 
En definitiva, hay pocas dudas de que los empresarios deben temer más una formalización de la investigación -por el daño en imagen- y a la prisión preventiva antes que a la condena misma. Una compensación que muestra un sistema que se ha constituido en una suerte de imbunche.

Una mención aparte, y en la que lamentablemente no es posible extenderse aquí, es la responsabilidad penal de las personas jurídicas. La OCDE exigía a Chile un sistema adecuado de responsabilidad de las empresas por el delito de cohecho a funcionario público extranjero, que si bien no debía ser penal, ${ }^{89}$ se optó, durante la tramitación de ley por reconocerle dicho carácter. ${ }^{90}$ Así, queda claro que no existía en el legislador especial interés en la regulación, sino que en ingresar a la OCDE, como se evidencia del propio mensaje de la ley. ${ }^{91}$ De todos modos, esto parece un gran avance en criminalizar las actividades empresariales. En su momento y ante el parlamento, Gonzalo Medina señaló que esta ley parecía como construir el piso 13 de un edificio que no tenía bases sólidas. Algo de razón tenía, porque aparte de algunos oasis, como un caso de cohecho en la comuna de Recoleta -que terminó sin condena- ${ }^{92}$ otro en la ciudad de Talca ${ }^{93}$ y este mismo de las universidades, esta ley ha sido -hasta ahora- apenas utilizada. La verdad es que la misma ley tiene muchas barreras internas para poder ser realmente relevante: (1) No se aplica a todos los delitos, sino que a una minoría: cohecho, financiamiento del terrorismo y lavado de activos. (2) Se necesita identificar la comisión de un delito por parte de un dependiente de la empresa, por lo que no combate la llamada "irresponsabilidad organizada", es decir, organizarse de tal manera que no haya una persona natural como culpable. (3) Requiere además un déficit organizacional de la empresa, o sea, que no esté constituida adecuadamente para prevenir delitos. (4) Esa organización se da por satisfecha teniendo un programa de prevención del delito o programa de compliance. (5) Además se puede certificar ese programa de compliance, lo que sería -a decir de una empresa certificadora- una inmunización contra la responsabilidad penal. ${ }^{94}$ (6) Por último, si nada de esto se hizo

\footnotetext{
${ }^{89} \mathrm{La}$ Convención para Combatir el Cohecho de Servidores Públicos Extranjeros en Transacciones Comerciales Internacionales establece expresamente en su artículo 3.2 que "Si, dentro del sistema jurídico de una de las Partes, la responsabilidad penal no es aplicable a las personas morales, ésta Parte deberá asegurar que éstas queden sujetas a sanciones eficaces, proporcionadas y disuasivas de carácter no penal, incluyendo sanciones pecuniarias, en casos de cohecho a servidores públicos extranjeros".

${ }^{90} \mathrm{El}$ proyecto enviado al Congreso denominaba a la responsabilidad del ente como "legal" (vid. historia de la Ley $\mathrm{N}^{\circ} 20.393$, p. 11). Durante la tramitación se optó por cambiar el adjetivo legal a penal siguiendo la opinión de algunos expertos. Así, por ejemplo, Clara SZCZARANSKI (Historia de la Ley $\mathrm{N}^{\circ} 20.393$, p. 36) y Gonzalo MEDINA Schulz (Historia de la Ley $\mathrm{N}^{\circ}$ 20.393, p. 54). Algo similar sucede en Italia -regulación usada como modelo para la Ley chilena- donde, si bien no se dice que la responsabilidad sea penal, sino que administrativa, se ha entendido que lo es. Vid. DE MAGLIE (2011), pp. 252 y 253.

${ }^{91}$ Vid. Historia de la Ley $\mathrm{N}^{\circ} 20.393$, pp. 6 y 7

92 Vid. un resumen del caso en ORTIZ (2013).

93 Sentencia del Segundo Juzgado de Garantía de Talca de 12.08.2013, en causa RUC 1201092968-5.

${ }^{94}$ In.compliance (no indica fecha).
} 
previamente, siempre es posible una suspensión condicional del procedimiento pagando una multa o estableciendo un programa de compliance.

\section{Cohecho entre privados}

Un asunto respecto del cual no parece haber situaciones que hayan llamado la atención del público chileno es el del cohecho en el ámbito privado. Se le paga, por ejemplo, a un dependiente de una empresa para que elija a un proveedor por sobre otro. Si se le pregunta a distintos ejecutivos de empresas, les dirán que esa es la forma en que se hace negocios. Muchos no lo consideran ni siquiera un problema. Por supuesto, en Chile no es delito.

$\mathrm{Al}$ respecto, es posible justificar brevemente el porqué es importante que se sancione: por una parte, es un atentado a la competencia, a la búsqueda de un funcionamiento adecuado de los mercados. Si ciertos actores obtienen ventajas más allá del servicio que ofrecen, el mercado pierde eficiencia. Pero, además, muchas veces hay otro interés público en el asunto. Dentro del modelo de Estado subsidiario que tenemos, la mayor parte de, por ejemplo, las obras públicas son realizadas por empresas privadas bajo el modelo de concesiones. En virtud de ello, no es solo un problema entre privados el cohecho en el ámbito comercial.

Dado que no tenemos una situación de este tipo que haya llamado la atención pública en Chile, parece adecuado hacer referencia a una extranjera: el caso Siemens. Siemens es una de las más importantes empresas alemanas, con presencia en todo el mundo. En la década pasada se descubrió que tenían un sistema estructurado para el pago de coimas a nivel global, que en nuestra región incluía a Argentina. Es, tal vez, el mayor escándalo de corrupción en la historia alemana. La condena penal que se produjo en Alemania, fue por el pago de ejecutivos de Siemens a ejecutivos de una empresa italiana de más de dos millones de euros para que se seleccionara a Siemens para la construcción de turbinas de gas, que si bien en primera instancia fue considerado como corrupción entre privados, finalmente la condena del BGH fue por administración desleal (tampoco sancionado en nuestro Derecho). ${ }^{95} \mathrm{Si}$ no se condenó por corrupción entre privados se debió a que el hecho fue cometido respecto de extranjeros, algo que en el estado actual de la ley alemana no es relevante ${ }^{96}$ y, por tanto, sería aplicable. En Chile, un caso semejante de corrupción habría quedado impune.

95BGH 2 StR 587/07, disponible en http://www.hrr-strafrecht.de/hrr/2/07/2-587-07.php, (consultado el 16.09.2013). Vid. especialmente parágrafo 17. La administración desleal se produce por el hecho de tener las llamadas "cajas negras" para el pago de coimas.

${ }^{96}$ KuHLEN (2013), pp. [1- 25] 3 y 4. 


\section{La Polar e Inverlink}

Por supuesto, el panorama no es, tampoco, completamente sombrío. ${ }^{97}$ Aun tipos como la estafa se hacen cargo de una buena parte de la criminalidad económica y a pesar de que no existe la administración desleal, muchos casos pueden ser resueltos mediante el tipo de apropiación indebida. Hay, además, áreas donde sí existe tipificación de algunas conductas. Podemos nombrar, por ejemplo, los delitos de la Ley General de Bancos ${ }^{98}$. Igualmente, respecto del mercado de valores, si bien la regulación sobre información privilegiada es poco aplicable, existen casos y hay claras normas, si bien con deficiencias, que sancionan la manipulación de los mercados. ${ }^{99}$ Igualmente existe la Ley $\mathrm{N}^{\circ} 19.233$ relativa a los delitos informáticos.

Es posible observar la existencia de estas posibilidades de persecución penal en los casos que respectivamente mayor atención de la prensa suscitaron en la presente década y en la década pasada: La Polar e Inverlink.

Respecto de Inverlink, cuyo escándalo estalló el año $2003,{ }^{100}$ si bien los hechos son previos a la entrada en vigencia en Santiago del Código Procesal Penal, lo que no permite observar la conducta del Ministerio Público en el asunto, sí es posible observar la forma cómo el Derecho penal chileno puede enfrentar asuntos originados en el seno de la actividad empresarial.

El caso se compone de distintas aristas. La primera es la llamada "Banco Central" y tiene cierto grado de independencia de las demás. Por un error en la digitación de la dirección del destinatario, que hizo que el correo electrónico "rebotara" generando un aviso, el presidente del Banco Central de ese entonces descubrió que su secretaria estaba enviando información reservada de la institución al CEO de Inverlink Enzo Bertinelli. Ella recibía, por esto, una contrapartida en dinero (según declaró, para comprar medicamentos). ${ }^{101}$ Distintos involucrados en este caso fueron condenados por delitos de cohecho, delitos contra el mercado de valores (información privilegiada) y por delitos informáticos, lo que quedó firme con la sentencia de la Corte Suprema rechazando la casación ${ }^{102}$ y, por tanto, ratificando la sentencia de la Corte Apelaciones de Santiago. ${ }^{103}$

\footnotetext{
${ }^{97}$ El propio Héctor Hernández señaló ante esta presentación que ya no corresponde una visión pesimista, considerando que ha habido avances y que al menos es hoy día un tema de debate.

${ }_{98}$ Otras referencias en HERNÁNDEZ (2005b) (nota 29), p. 122, nota al pie 69.

99 Sin perjuicio de ello, existe una sola sentencia al respecto -que también involucra uso de información privilegiada, en el contexto del caso "Schwager"-. Sobre eso vid. RoSENBLUT (2011). Vid. sobre la manipulación bursátil el reciente artículo de LONDOÑO (2013).

${ }^{100}$ La primera nota de prensa al respecto corresponde a EMOL (2003).

101 ARAVENA y SALVAT (2003).

102 En dicha sentencia se hace el resumen de condenas: a Paola Andrade, secretaria del Presidente del Banco Central, se la condena en primera instancia por cohecho del artículo 248 bis del CP y el artículo $4^{\circ}$ de la Ley $\mathrm{N}^{\circ} 19233$ (difundir o revelar datos contenidos en un sistema informático). Posteriormente la Iltma. Corte de Apelaciones revoca la sentencia en cuanto a la absolución por el
} 
$\mathrm{Al}$ descubrirse estos hechos se produce una corrida bancaria ${ }^{104}$ donde los inversores intentan retirar su dinero de manera anticipada. Esto implica que Inverlink se quedara sin patrimonio para responder a quienes habían invertido fondos con ellos.

A partir de esto se origina la arista más mediática, que es la que involucra a la Corfo. ${ }^{105} \mathrm{El}$ operador de la mesa de dinero de Corfo habría endosado a Inverlink -a través de su principal socio Eduardo Monasterio- certificados de depósito de la Corfo por miles de millones de pesos. Inverlink, a su vez, vendía los documentos como propios, pero con pacto de retroventa. De esta manera los recuperaba antes de su vencimiento y los devolvía a la Corfo, que, como institución, no se percataba de la sustracción. Una vez producida la corrida bancaria, por supuesto, no fue posible recuperar los documentos. En este ámbito, se dictó la acusación a principios de enero de 2012 por los delitos de malversación de caudales públicos, estafa, infracción a la Ley de Mercado de Valores, de bancos y cohecho. ${ }^{106} \mathrm{La}$ sentencia, luego de más de diez años de investigación, todavía se encuentra pendiente.

Vinculado a esto está el cuaderno de "triangulaciones", en que fueron corredoras de bolsa las que comercializaron en el mercado dichos títulos. En este cuaderno ya existe un fallo absolutorio en primera instancia, sin perjuicio de lo cual quedan recursos pendientes. ${ }^{107}$

Por otra parte, existen querellas de quienes invirtieron en Inverlink -muchos de ellos personas naturales-, principalmente por estafa y apropiación indebida, en consideración a que los documentos que habrían recibido por parte de Inverlink no serían reales y porque no se habrían hecho las inversiones encargadas, todo esto como parte de la causa principal.

En la llamada arista "tributaria" se persiguió a los miembros del holding Inverlink por presentación de declaración de impuestos maliciosamente incompleta o falsa (art. $97 \mathrm{~N}^{\circ} 4$ del Código Tributario). Aquí existe ya también

\footnotetext{
delito del artículo 60 letra h y g de la Ley 18.045 de Mercado de Valores (revelar información privilegiada y utilizarla), sancionándola también por dicho delito. Enzo Bertinelli es sancionado por el cohecho del art. 250 del CP y, con la sentencia de la Corte, también por los delitos contra el mercado de valores. Ellos eran los principales involucrados en este hecho, aunque se condena a varias personas más, incluido Eduardo Monasterio. SCS 08.11.2012 Rol 2249-2012.

103 SCA de Santiago 22.11.2011 rol 992-2010.

104 Sin perjuicio de que Inverlink no era realmente un banco, a pesar de haber intentado obtener una licencia bancaria. Vid. EMOL (1999).

105 Esto se produce los primeros días de marzo de 2003. Vid. EMOL (2003).

106 ULLOA (2012).

107 Vid. por ejemplo, ElguETA (2013).
} 
sentencia condenatoria de término por parte de la Excma. Corte Suprema, revocando la sentencia absolutoria de primera instancia. ${ }^{108}$

Por último, para completar el cuadro, al estallar el escándalo, Monasterio, según lo ha confirmado la Excma. Corte Suprema, habría simulado un contrato de compraventa para traspasar la propiedad de un inmueble a su cónyuge, causa respecto de la cual también se condenó a los involucrados. ${ }^{109}$

El otro caso al que se ha hecho referencia es el que involucra a "La Polar". El fiscal de la causa, José Morales, anunció que durante septiembre de 2013 presentaría la acusación en la causa, ${ }^{110}$ lo que hasta la entrega de este trabajo no se había producido, razón por la que puede ser precipitado hacer un análisis más profundo. Como es sabido, esto se presentó como un gran escándalo por las repactaciones unilaterales que hizo la empresa de las deudas de los clientes, dando, con esto, información falsa sobre la situación económica de la empresa. ${ }^{111}$ Así, las hipótesis por las que se podría acusar -y por las cuales se formalizó la investigación ${ }^{112}$ - tienen que ver con infracciones a la Ley $\mathrm{N}^{\circ} 18.045$ de Mercado de Valores, en cuanto a otorgar información falsa a la Superintendencia de Valores y Seguros, otorgar información falsa al mercado y uso de información privilegiada; a la Ley General de Bancos (DFL N ${ }^{\circ} 3$ de 1997), por utilizar información falsa para obtener créditos y, posteriormente, por entregar información falsa a la Superintendencia de Bancos; ${ }^{113}$ y lavado de activos.

No cabe todavía, como se ha señalado, hacer un análisis acabado del caso La Polar, considerando la complejidad de los hechos y la cercanía de la acusación del Ministerio Público. Igualmente, dado que todavía no existe en sentencia en el cuaderno principal no cabe hacer un análisis de lo sucedido en Inverlink.

De todos modos, es conveniente considerar algunas cosas. Por un lado, existe una evidente dispersión normativa que lleva a preguntarse en qué medida no se está incurriendo en problemas de vulneración del non bis in ídem. Así, en Inverlink, llama la atención de la triple valoración que se hace del hecho en la arista "Banco Central". Posiblemente algo similar pase con la arista "Corfo". En La Polar, cabe preguntarse si informaciones derivadas de un mismo hecho, pero entregadas a múltiples instituciones pueden ser objeto de valoraciones diversas.

Además, en ambos casos es posible ver que ante la situación de corrupción que penetra de forma tan profunda la empresa, constituyéndose una verdadera

\footnotetext{
108 SCS de 17.11.2010 Rol 297-2009.

${ }^{109}$ SCS de 14.12.2012 Rol 2025-2012

110 GONZÁLEZ (2013).

111 Una buena explicación del caso en BAIRES, SulLIVAN y CHÁvEZ (2011).

112 Audio de la resolución respecto de la prisión preventiva por parte del $2^{\circ}$ Juzgado de Garantía de Santiago disponible en PODERJUDICIAL.CL (2011).

113 Fiscalía Región METROPOLITANA CENTRO NORTE (2013).
} 
"actitud criminógena de grupo", 114 es posible contar con herramientas para combatir el hecho desde el Derecho penal. Sin embargo, en este ámbito hay un proceso que está avanzando de lo represivo a lo preventivo. ${ }^{115} \mathrm{Si}$ bien un Derecho penal de la prevención, en el sentido de que adelante la punibilidad a meros actos administrativos o preparatorios mediante el uso indiscriminado de delitos de peligro abstracto es criticable, es una realidad que en el caso de las empresas existe una diversificación de los organismos de vigilancia no penales, cuyos controles han, indudablemente, fallado en estos casos. Dicha vigilancia se produce en tres ámbitos: estatal, gatekeepers y control interno o programas de compliance.

Tal como lo fueron Enron en EE.UU. ${ }^{116}$ o Siemens en Alemania, ${ }^{117}$ Inverlink ${ }^{118}$ y La Polar, ${ }^{119}$ así como sus directivos, eran empresas especialmente destacadas en el mercado. Por eso se hace sorprendente cómo todos los ámbitos de fiscalización pudieron fallar.

En cuanto a los llamados gatekeepers, estos son intermediarios que verifican o certifican ciertos servicios, entre ellos, los estados financieros, el merecimiento de crédito, su comparación con otras empresas de la competencia o garantizando la corrección de una determinada transacción. ${ }^{120}$ En ese sentido, las instituciones auditoras juegan un rol fundamental para determinar la credibilidad de la empresa para inversores que no están en condiciones de analizar ellos mismos el estado de la compañía. Tal como sucedió en Enron, ${ }^{121}$ en el caso de La Polar no cabe duda sobre el fallo de la empresa auditora, que incluso fue sancionada con 8.000 UF por la Superintendencia de Valores y Seguros. ${ }^{122}$ A esto se sumó la sanción de la Unidad de Análisis Financiero -entidad encargada de la prevención de lavado de activos en Chile- por no informar operaciones sospechosas relacionadas con La Polar. ${ }^{123}$

En el caso de Inverlink no es muy distinto, toda vez que, además de las ya referidas situaciones penales, existen multas a dos corredoras de bolsa, ratificadas

\footnotetext{
114 Concepto acuñado por SCHÜNEMANN (1979), p. 22.

115 Sobre cómo afecta esto al Derecho penal, en el contexto de la llamada sociedad del riesgo, vid. ROTSCH (1998), pp. 54 y ss. Laufer destaca que en los EE.UU. en los años sesenta y setenta empieza a desarrollarse un proceso regulatorio que implica la creación de cientos de miles de normas penales. LAUFER (2006), p. 26.

116 Ibidem, pp. 99 y 100.

117 Siemens era incluso el primer y más importante miembro corporativo del capítulo alemán de Transparencia Internacional. Vid. GRAEFF y WOLF (2011).

118 Eduardo Monasterio era considerado el "rey Midas del sistema financiero". García (2004).

119 En diciembre de 2009 se destacaba al presidente de La Polar, Pablo Alcalde, como el mejor ejecutivo de la década. COMUNICAEXTEND (2009).

${ }^{120}$ Cfr. COFFE (2002), p. [1403-1420] 1405.

121 Ibídem, passim.

122 Resolución Exenta Nº63 de 9 de marzo de 2012 de la Superintendencia de Valores y Seguros.

123 Resolución Exenta D.J. N 106-764-2012 de 07.08.2012 Rol 013-2011 de la Unidad de Análisis Financiero.
} 
por la Corte Suprema, ${ }^{124}$ debido a que dependientes de dichas instituciones intermediaron para que Inverlink pudiera operar con Corfo, siendo que había prohibición de ello.

Cabe preguntarse en qué medida son también responsables los órganos de fiscalización estatal. Ya se ha hecho referencia a los cuestionamientos al Sernageomin en el caso de la mina San José. ${ }^{125}$ En el caso Inverlink se interpuso una demanda contra la Superintendencia de Valores y Seguros por no ejercer sus obligaciones de vigilancia, cuyo rechazo fue ratificado - en fallo dividido- por la Corte de Apelaciones de Santiago. ${ }^{126}$

Por último, parece también claro que han fallado los controles internos. Desde hace algún tiempo en el mundo ${ }^{127}$ se ha iniciado una verdadera "revolución del compliance", ${ }^{128}$ entendido este en sentido penal como las medidas que adopta una empresa para impedir que se cometan delitos al interior de ella. ${ }^{129}$ En Chile, en materia penal, este tipo de programas son promovidos ${ }^{130}$ por la Ley $\mathrm{N}^{\circ} 20.393$ para la prevención solo de los delitos respecto de los cuales las personas jurídicas pueden ser hechas responsables -cohecho, financiamiento del terrorismo y lavado de activos- y solo como forma de evitar la responsabilidad penal del ente. Es de esperarse que el ámbito de aplicación, al menos de manera fáctica, se amplíe sustancialmente, reconociéndose la necesidad al interior de las empresas de contar con este tipo de programas. ${ }^{131}$

Un último aspecto que vale la pena considerar es cuál será, en ambas investigaciones, la reacción punitiva que en definitiva se produzca. Potenciales absoluciones o beneficios de la Ley 18.216 que se pudieran otorgar pondrían en entredicho la eficacia del Derecho penal al enfrentar los dos mayores escándalos que se han producido en Chile en materia de actividades empresariales.

\footnotetext{
124 SCS de 27.05.2011 Rol 474-2009 y SCS de 27.05.2011 Rol 276-2010.

125 Vid. infra 4.

126 SCA de 28.12.2012 Rol 2.947-2011.

127 Sobre el desarrollo del Compliance en EE.UU. y Alemania, vid. ROTSCH (2012), pp. [45-75] 50-58.

128 Así PieTH (2011), pp. 75-84.

129 Más específica es la definición de Rotsch, como "la totalidad de las medidas lícitas para la prevención de la responsabilidad penal de los dependientes de la empresa en base a comportamientos relacionados con la actividad de la misma" (la traducción es nuestra). ROTSCH (2012) (nota 127), p. 48.

${ }^{130} \mathrm{El}$ artículo $3^{\circ}$ de la Ley establece que solo será penal responsable las personas jurídicas en la medida que sean consecuencia del incumplimiento de sus deberes de dirección y supervisión y que dichos deberes se habrán cumplido cuando hubiere adoptado un modelo de prevención del delito, cuyas bases están en el artículo $4^{\circ}$ de la misma Ley. Así, no hay obligación de establecer el sistema de compliance, pero sí la promoción de su establecimiento mediante el benefício de no ser penalmente responsable.

${ }^{131}$ El impulso en Alemania puede atribuírselo a la imputación de responsabilidad “top-down”, es decir, la atribución de la responsabilidad en primera línea a los directivos de la empresa que, para evitar esto, comienzan a implementar los programas de prevención. Vid. ROTSCH (2008), p. 7.
} 


\section{Recurso al Derecho penal en otras áreas}

Alguien podría señalar que la preterición legislativa, aquí esbozada, de actualizar los delitos económicos tiene su correlato en los otros delitos. Esto no es efectivo y hay una prolífica producción de legislación penal en los últimos años. Una de las más destacadas es la a todas luces desproporcionada Ley $\mathrm{N}^{\circ} 20.000$ sobre tráfico ilícito de estupefacientes, donde no solo hay tipos penales demasiado amplios, sino que hay penas sumamente altas e incluso hay un relajo de las garantías procesales. Algo similar sucede con la Ley $\mathrm{N}^{\circ} 18.314$, llamada Antiterrorista, que si bien no es tan reciente, ha sufrido modificaciones -casi siempre intensificando la persecución- el 2002, el 2003, 2005 y 2010.

Pero incluso hay una tendencia a que la legislación, en lugar de criminalizar las actividades de las grandes empresas, más bien busca protegerlas de la criminalidad tradicional. Cómo se explica, si no, que se hayan creado normas especiales para adelantar la punibilidad del hurto hormiga, es decir, el que sustrae unos calcetines en La Polar o un chocolate del mostrador de una farmacia. ${ }^{132}$ Sorprendente es, por ejemplo, que se haya creado una ley especial para sancionar el robo de cables de cobre. ${ }^{133}$

Esto pasa con materias que también son económicas. Delitos como los de la Ley $\mathrm{N}^{\circ} 19.039$ de propiedad industrial, si bien a veces sirven para perseguir actividades de empresas, más bien sirve para perseguir a "piratas" callejeros. El uso fraudulento de tarjetas bancarias también sirve principalmente para perseguir a ciudadanos que están muy lejos de participar en las esferas del poder.

Incluso normas que tienen como núcleo la regulación de instituciones financieras, como la Ley $\mathrm{N}^{\circ} 19.913$ que crea la Unidad de Análisis Financiero, que buscando prevenir y sancionar el lavado de activos, termina siendo utilizada para sancionar, por ejemplo, a una mujer que, ante la entrada inminente de la policía, escondió en el entretecho de su casa el dinero que su pareja obtuvo con la venta de drogas. ${ }^{134}$

\section{Resumen y conclusiones}

En este breve repaso, si bien se ha intentado abarcar lo más posible, no ha sido posible ser exhaustivo. No se han revisado otros elementos que pueden ser de importancia en Derecho penal sustantivo, procesal y ejecución de las sentencias. No se ha hecho referencia a ausencias sensibles en nuestra legislación como una estafa

\footnotetext{
${ }^{132}$ Ley $\mathrm{N}^{\circ} 19.950$ de 05.06.2004.

${ }^{133}$ Ley N $\mathrm{N}^{\circ} 20.273$ de 28.06.2008.

134 SCA San Miguel, 07.09.2011, Rol 993-2011.
} 
informática ${ }^{135}$ o a la subutilización, por motivos principalmente dogmáticos ${ }^{136}$ y en comparación con otros ordenamientos, de la estafa tradicional. No se ha podido tampoco hacer referencia a, por ejemplo, los acuerdos reparatorios en delitos de contenido patrimonial, donde, de hecho, el imputado puede simplemente pagar para evitar la responsabilidad penal ${ }^{137}$ o el control de la acción que tiene el Servicio de Impuestos Internos en los delitos tributarios. ${ }^{138}$ En el ámbito de ejecución de la pena, Jonatan Valenzuela puso hace poco el acento en que el sistema permite que quienes tienen dinero puedan pagar para mejorar su situación intracarcelaria. ${ }^{139}$

Todo lo que se ha dicho acá, en realidad, debiera tener poco de novedoso. En febrero de 2012 Enrique Alcalde publicó una columna en El Mercurio donde criticaba la tendencia a la "huida al Derecho penal" en materia de regulación económica, es decir, cómo habría una tendencia a regular penalmente asuntos económicos, lo que implicaría renunciar a ciertos principios del Derecho penal. ${ }^{140}$ Esta es una idea que se comenta mucho en el extranjero y que algún eco tiene entre los penalistas nacionales, ${ }^{141}$ pero ¿es posible sostener que en Chile también es así? Sintomático es que Alcalde no haya dado ni un solo ejemplo al respecto, sin perjuicio de que las columnas deben ser breves. Héctor Hernández, tal vez quien con mayor profundidad ha estudiado el fenómeno de la delincuencia económica desde el punto de vista del Derecho penal en Chile, respondió a Alcalde que '[...] hablar de una 'huida al derecho penal' en materia económica tiene toda la apariencia de un ejercicio fino de humor". ${ }^{142}$ El mismo Hernández el año 2005 identificó vacíos permanentes, normas temibles sin aplicación y normas temibles poco aplicables en el ámbito de nuestra regulación penal económica, ${ }^{143}$ trabajo en el que también señaló que:

[C]iertamente no es tarea del sistema penal la promoción de la justicia social, pero sí al menos cabe exigirle que no se constituya en fuente de desigualdad, que es precisamente lo que hace si persiste en ensañarse con conductas desviadas, características de las posibilidades de relación social de los sectores menos favorecidos y simplemente

\footnotetext{
135 Entendiendo que un requisito de la estafa es la necesidad de una disposición patrimonial realizada por el engañado, no es posible que el tipo se aplique a casos de obtención de datos de manera fraudulenta (phishing). En efecto, lo que se hace es que bajo pretextos falsos se obtienen los datos para acceder a las cuentas bancarias, pero el retiro del dinero lo hace el propio delincuente, sin que intervenga

${ }^{136}$ La exigencia de Etcheberry, de que el engaño debe ser un mise en scène o puesta en escena es ampliamente aceptado por nuestra jurisprudencia. Vid. ETCHEBERRY (1998), pp. 392-396.

${ }^{137}$ Artículos 241 y ss. del Código Procesal Penal.

138 Artículo 162 del Código Tributario.

139 VALENZUELA (2013).

140 AlCALDE (2012).

141 Algunas referencias a ello: Desde el punto de vista del principio de ultima ratio, CARNEVALI (2008), p. 26.

142 HERNÁNDEZ (2012).

143 HERNÁNDEZ (2005b) (nota 29), passim.
} 
ignora aquéllas equivalentes en el contexto de relación de los sectores más acomodados. ${ }^{144}$

Gonzalo Medina, en una clara carta publicada en El Mercurio se refiere a cómo las reformas en materia económica no han ido acompañadas de una modernización de la legislación penal. ${ }^{145}$ En el mismo sentido de Hernández, los profesores José Muñoz Lorente y José Ángel Fernández han dicho que en Chile "[...] hoy sigue existiendo una Justicia penal de o para los pobres y una Justicia penal de o para los poderosos". ${ }^{46}$

De todos modos, parece importante aportar las conclusiones de lo que puede verse de revisar los casos que hemos visto: (1) Hay ámbitos importantes de actividades empresariales ilícitas para las que el legislador no ha establecido sanciones penales; (2) eso obedece a una decisión consciente del legislador de no incriminar o derechamente de eliminar la sanción penal de esas conductas (3) esto se complementa con problemas dogmáticos a los que se ven enfrentados los tribunales y cuyas soluciones no han querido modernizar; (4) el Ministerio Público se ve obligado por la opinión pública a iniciar investigaciones con poca viabilidad en la práctica, ya sea porque debe utilizar tipos penales que dudosamente se aplican o buscar castigar por otros hechos que los que dieron inicio a la investigación, donde, además, las amenazas de pena son muy bajas; (5) normalmente esto hace que los procesos terminen por salidas alternativas o con penas muy bajas que aumentan la sensación de impunidad; y (6) muchas veces se exagera el uso de la prisión preventiva como forma de lograr al menos algún tipo de perjuicio para los imputados. (7) En algunos casos, derechamente no hay un interés muy intenso del Ministerio Público en la persecución.

Para terminar, es importante preguntarse el significado ideológico de lo que se ha planteado acá. Alguno podría pensar es que es un destemplado ataque a la empresa como unidad de producción o actor social; o un intento por desestabilizar el "sistema neoliberal". Lo más grave de todo esto es que, sin embargo, lo que aquí se dice no tiene nada de revolucionario. Un sistema basado en libre mercado implica cierto grado de confianza en el funcionamiento de esos mercados. Eso implica que la competencia se dé en términos justos. Si parte de los partícipes en el mercado no siguen las reglas, esto se constituye como una barrera de entrada que perjudica la competencia. ${ }^{147}$ En definitiva, en la medida que la

\footnotetext{
144 Ibidem, p. 103.

145 MEDINA (2010).

146 MuÑOZ y FERNÁNDEZ (2010) (nota 34), p. 416.

147 Este es un análisis independiente del bien jurídico "libre competencia". Dentro de la teoría moral de los delitos de cuello blanco, GREEN (2006) supone que subyace a ellos una ilicitud basada en la violación de una norma moral ordinaria (everydaynorm) (Ibidem, p. 45-46). Dentro de ellas distingue a hacer trampa (cheating) consistente en violar una regla para obtener una ventaja respecto de una parte con la que está en una relación cooperativa y regulada por normas (Ibídem, p. 57). Esto, como se ve, atenta contra la competencia, pero incluso respecto de delitos con otros bienes jurídicos. Un ejemplo es el uso de información privilegiada (Ibídem, p. 241 y ss.). Ahora bien,
} 
Winter - Derecho penal e impunidad empresarial en Chile

imposición de sanciones penales sirva para prevenir las infracciones legales, las empresas que buscan realizar las cosas de manera correcta debieran pedir más y no menos Derecho penal.

incluso más allá de cual sea primariamente la falta moral, la mayoría de los delitos cometidos a través de una empresa conllevan una afectación a la competencia. Así, un delito como el cohecho, si bien desde el punto de vista del bien jurídico afecta la probidad administrativa y moralmente está más cercano a una deslealtad (Ibídem, pp. 200 y ss.), también implica una ventaja para la empresa que realiza el cohecho. 


\section{BIBLIOGRAFÍA}

24HORAS.CL (2012):“Caso farmacias: Fiscalía pide 5 años de pena remitida”, (consultado le 28.08.2013). Disponible en: http://www.24horas.cl/nacional/caso-farmacias-fiscalia-pide-5-anos-depena-remitida- 230241

* ABRAMOVICH, Paulina (2013): "Tres años después, se cierra sin acusados caso de los 33 mineros de Atacama”, (consultado el 28.08.2013). Disponible en:

http://www.google.com/hostednews/afp/article/ALeqM5h7eG5kmseuwWv2wvXetUf64zaXow? docId=CNG.ad05a092be854796e14eb257ce8a738a.311\&hl=es

* ALCALDE, Enrique: (2012): “La regulación económica y su huída al derecho penal”, (consultado el 26.08.2013). Disponible en:

http://www.elmercurio.com/Legal/Noticias/Analisis-Juridico/2012/02/03/La-regulacioneconomica-y-su-huida-al-derecho-penal.aspx

* ARAVENA, Pamela y SALVAT, Montserrat (2003): "Los secretos de la secretaria. Pamela Andrada. de La Moneda a Capuchinos", (consultado el 06.12.2013). Disponible en: http://diario.elmercurio.com/detalle/index.asp?id=\{ddb099f1-a311-4164-ae64-dc3ecb068c09\}

* ARGANDOÑA, Consuelo (2010): "PDI realiza peritajes a computadores de minera y Sernageomin de Atacama”, (consultado el 13.09.2013). Disponible en: http://diario.latercera.com/2010/08/25/01/contenido/pais/31-36529-9-pdi-realiza-peritajes-acomputadores-de-minera-y-sernageomin-de-atacama.shtml

* BAIRES, Rodrigo, SULLIVAN, Jorge y CHÁVEZ, Andrés (2011): “La Polar: Un mapa para entender cómo se fraguó y ejecutó el lema de 'llegar y llevar”, (consultado el 26.08.2013). Disponible en: http://ciperchile.cl/2011/07/08/la-polar-un-mapa-para-entender-como-se-fraguo-y-ejecuto-ellema-de- $\%$ E2 $\% 80 \% 9$ Cllegar-y-llevar $\% \mathrm{E} 2 \% 80 \% 9 \mathrm{D} /$

* BASCUÑ́́n, Antonio (2008): “Comentario crítico a la regulación de los delitos contra el medio ambiente en el anteproyecto de Código Penal de 2005", (consultado el 02.12.2013). Disponible en: http://www.cepchile.cl/1 4161/doc/comentario critico a la regulacion de los delitos contra el medio ambiente en e.html\#.Up3dAtKk-m4

* BERNEDO, Patricio (2013): Historia de la libre competencia en Chile 1959-2010 (Fiscalía Nacional Económica, Santiago).

* BOGOLASKY, Natalia (2011): "En este momento la profesión del auditor está en el mismo papel que el cura pedófilo", (consultado el 26.08.2013). Disponible en:

http://ciperchile.cl/2011/12/01/en-este-momento-la-profesion-del-auditor-esta-en-el-mismopapel-que-el-cura-pedofilo/

* CAMPOS, Constanza (2012): "Conozca los hitos que marcaron el conflicto de Freirina hasta el cierre de la planta”, (consultado el 13.09.2013). Disponible en:

http://www.economiaynegocios.cl/noticias/noticias.asp?id=104332

* CARNEVALI, Raúl (2008): "Derecho Penal como ultima ratio. Hacia una política criminal racional", en Ius et Praxis 14( $\left.\mathrm{N}^{\circ} 21\right)$ pp. 13-48.

* COFFE, John C, Jr. (2002): Understanding Enron: "It's About the Gatekeepers, Stupid”, en The Business Lanyer (vol. $57 \mathrm{~N}^{\circ}$ 4) pp. 1403-1420.

* COMUNICAEXTEND (2009): "Presidente de La Polar fue elegido el mejor ejecutivo de la década", (consultado el 09.12.2013). Disponible en:

http://www.extend.cl/comunica/2009/12/29/presidente-de-la-polar-fue-elegido-el-mejorejecutivo-de-la-decada/

* DE MAGLIE, Cristina (2011): “Countries with criminal liability: Italy", en Gobert, James y Pascal, Ana María, European Devolpment in Corporate Criminal Liability, (Ed. Routledge, Londres-Nueva York).

* DesormenauX, Paulette y RAMÍreZ, Pedro (2012): "Freirina: Dos nuevos estudios cuestionan calidad de las aguas que beben los cerdos de Agrosuper", (consultado el 13.09.2013). Disponible en: http://ciperchile.cl/2012/12/06/freirina-dos-nuevos-estudios-cuestionan-calidadde-las-aguas-que-beben-los-cerdos-de-agrosuper/ 
Winter - Derecho penal e impunidad empresarial en Chile

* DIRECCIÓN REGIONAL CONAMA Xa REGIÓN DE LOS LAGOS Y UNIVERSIDAD AUSTRAL DE CHILE (2005): "Informe Final - Estudio sobre origen de mortalidades y disminución poblacional de aves acuáticas en el Santuario de la Naturaleza Carlos Andwandter, en la provincia de Valdivia" (consultado el 02.09.2013). Disponible en: http://www.ceachile.cl/Cruces/PDF/25.\%20Informe \%20final \%20UACh.pdf

* DONOSO, Pamela (2009): "La rebelión de los consumidores" (consultado el 28.08.2013). Disponible en: http://www.elmostrador.cl/pais/2009/04/07/la-rebelion-de-los-consumidores/

* EL CIUDADANO (2009): "Farmacias Ahumada 'compensará' a clientes", (consultado el 28.08.2013). Disponible en: http://www.elciudadano.cl/2009/04/16/7314/farmacias-ahumada$\% \mathrm{E} 2 \% 80 \% 98$ compensara $\% \mathrm{E} 2 \% 80 \% 99$-a-clientes/

* ELGUETA, Enrique (2013): "Caso Inverlink: Corfo sufre revés para recomponer el jarrón perdido", (consultado el 06.12.2013). Disponible en: http://www.pulso.cl/noticia/empresamercado/empresa/2013/10/11-31135-9-caso-inverlink-corfo-sufre-reves-para-recomponer-eljarron-perdido.shtml

(2012): "Justicia pone fin al caso Montaner y Guzmán”, (consultado el 13.09.2013). Disponible en: http://www.pulso.cl/noticia/actualidad-politica/actualidad/2012/10/2-12282-9justicia-pone-fin-al-caso-montaner-y-guzman.shtml

* EL MOSTRADOR (2013): "Fiscal Nacional abre investigación ante denuncia criminal por lucro en universidades", (consultado el 13.09.2013). Disponible en:

http://www.elmostrador.cl/pais/2012/06/20/fiscal-nacional-abre-investigacion-ante-denunciacriminal-por-lucro-en-universidades/

* EMOL (2003): "Banco Central se querella contra receptores de informes confidenciales", (consultado el 06.12.2013). Disponible en:

http://www.emol.com/noticias/nacional/2003/02/03/103986/banco-central--se-querella-contrareceptores-de-informes-confidenciales.html

(2003): "Corfo se querella contra responsable de millonario robo", (consultado el 06.12.2013).

Disponible en: http://www.emol.com/noticias/nacional/2003/03/08/106385/corfo-se-querellacontra-responsable-de-millonario-robo.html

(2011): "Ejecutivos de La Polar quedaron en prisión tras extensa audiencia", (consultado el 24.09.2013). Disponible en: http://www.emol.com/noticias/economia/2011/12/16/517332/xxx.html (1999): "Inverlink pidió licencia bancaria".

* ERNST, Daniel R (1990):: “The new antitrust history”, N. Y. L. Sch. L. Rev. (879), pp. 879-891.

* ETCHeberry, Alfredo (1998): Derecho Penal - Parte Especial, T. iii (Ed. Jurídica de Chile, Santiago).

* FERrando, K., TORRES, C. (2011): "Cinco imputados en caso D\&S-Falabella alcanzan acuerdo con fiscalía”, (consultado el 26.08.2013). Disponible en:

http://diario.latercera.com/2011/02/08/01/contenido/negocios/10-58717-9-cinco-imputados-encaso-d-sfalabella-alcanzan-acuerdo-con-fiscalia.shtml

* Fiscalía REgión METROPOLITANA CENTRO NORTE (2013): “La Polar: Fiscalía Centro Norte formalizó por nuevo delito a ejecutivos de multitienda", (consultado el 16.09.2013). Disponible en: http://www.fiscaliadechile.cl/Fiscalia/fiscalias metroCentroNorte/noticias det.do?id=3990

* GARCÍA, Daniel (2004): “El último día de Monasterio", (consultado el 09.12.3013). Disponible en: http://diario.elmercurio.com/detalle/index.asp?id $=\{3 \mathrm{a} 68 \mathrm{e} 694-5898-44 \mathrm{a} 3-9 \mathrm{~d} 36-5 \mathrm{efb} 52147 \mathrm{aa} 6\}$ 
* GONZÁLEZ, Andrea (2013): “Caso La Polar: Fiscalía presentará acusación en septiembre”, (consultado el 26.08.2013). Disponible en: http://www.emol.com/noticias/nacional/2013/07/29/611582/caso-la-polar-fiscalia-preparaacusacion-contra-imputados-para-septiembre.html

* GRAEFF, Peter y WOLF, Sebastian (2011): “Transparency International, der Korruptionsfall Siemens und einige wissenschaftliche Folgerungen", en Weidenfeld, Ursula (Ed.), Nütrliche Anwendungen? Der Fall Siemens und die Lehren für das Unternehmen, die Industrie und Gesellschaft, (ed. Piper, München), pp. 55-74.

* GREEN, Stuart P. (2006): Lying, Cheating, and Stealing. A Moral Theory of White-Collar Crime (Oxford University Press, New York).

* HEFENDEHL, Roland (2008): “Derecho penal medioambiental: ¿Por qué o cómo?”, (consultado el 03.12.2013). Disponible en http://www.cepchile.cl/dms/lang 1/doc 4159.html\#.Up3Y9tKk-m4

* HERNÁNDEZ, Héctor (2012): “¿Huida al derecho penal en materia económica en Chile?”, (consultado el 26.08.2013). Disponible en http://www.elmercurio.com/Legal/Noticias/AnalisisJuridico/2012/03/09/Huida-al-derecho-penal-en-materia-economica-en-Chile.aspx

(2006): “El problema de la 'causalidad general' en el derecho penal chileno (con ocasión del art. 232 del Anteproyecto de Nuevo Código Penal)". Política Criminal ( $\mathrm{N}^{\circ}$ 1), pp. 1-33. (2005a): "La administración desleal en el Derecho Penal Chileno", Revista de Derecho de la Pontificia Universidad Católica de Valparaiso XXVI, (I), pp. 201 y ss.

(2012): "La punibilidad de la colusión (secreta) de precios en el derecho chileno", en Politica criminal ( $\left.\mathrm{N}^{\circ} 13\right)$, pp. 147- 167.

(2005b): "Perspectivas del Derecho penal económico en Chile", Persona y Sociedad Vol. XIX (No 1), pp. 101-134.

* IN.COMPLIANCE (no indica fecha): "Certificación de los modelos de prevención de delitos (Ley 20.393)", (consultada el 12.02.2012). Disponible en:

http://www.incomp.cl/Incompliance/certificacion-de-los-modelos-de-prevencion-de-delitos-ley$\underline{20393}$

* KUHLEN, Lothar (2013): “Grundfragen von Compliance und Strafrecht”, en Kuhlen, Lothar, Kudlich, Hans, Ortiz de Urbina, Íñigo, Compliance und Strafrecht, C.F. Müller, (Heidelberg-MünchenLendsberg-Hamburg), pp.1- 25.

* LA NACIÓN (2009a): "Chahuán descarta nombrar fiscal exclusivo por caso farmacias", (consultado el 28.08.2013). Disponible en: http://www.lanacion.cl/prontus noticias v2/site/artic/20090407/pags/20090407235001.html (2009b): "No prendió en usuarios llamado a no comprar", (consultado el 28.04.2013).

Disponible en:

http://www.lanacion.cl/prontus noticias v2/site/artic/20090407/pags/20090407235756.html

(2009c): "Piñera: Uso de información privilegiada fue una 'mera falta administrativa", (consultado el 26.08.2013). Disponible en: http://www.lanacion.cl/noticias/site/artic/20090104/pags/20090104130456.html

* LA TERCERA (2012): "El empresario y el caso que remeció a las universidades", (consultado el 13.09.2013). Disponible en http://diario.latercera.com/2012/12/01/01/contenido/reportajes/25124308-9-el-empresario-y-el-caso-que-remecio-a-las-universidades.shtml

* LAUfER, William S. (2006): Corporate Bodies and Guilty Minds, The failure of Corporate Criminal Liability, (The University Chicago Press, Chicago).

* LONDOÑO, Fernando (2013): "Tlícito de manipulación bursátil y lesividad. Aspectos de política sancionatoria”, Politica Criminal Vol. 8 (N 15), pp. 64-127. 
Winter - Derecho penal e impunidad empresarial en Chile

MATUS, Jean Pierre (2013): "De nuevo sobre la falta de punibilidad de los atentados contra la libre competencia, de conformidad con el Art. 285 del Código penal - Algunos aspectos de la discusión con Héctor Hernández en Política Criminal", Politica Criminal (N 15), pp. 314 a 362.

(ed.) (2004): Derecho Penal del Medio Ambiente - Estudios y propuesta para un nuevo Derecho penal ambiental chileno (Ed. Jurídica de Chile, Santiago).

(2008): "Fundamentos y propuesta legislativa para una nueva protección penal del medio ambiente en Chile, elaborada por la Comisión Foro Penal” (ZIS 7), pp. 304-324.

(2012): "Sobre la falta de punibilidad en Chile de los acuerdos de precios", Política Criminal $\left(\mathrm{N}^{\circ}\right.$ 14), pp. 318-356.

* MAY, James (1987): "Antitrust Practice and Procedure in the Formative Era: The Constitutional and Conceptual Reach of State Antitrust Law, 1880-1918”, University of Pennsylvania Law Review (Vol. 135, $\left.\mathrm{N}^{\circ} 3\right)$, pp. 495-593.

* MEDINA, Gonzalo (2010): "Las otras reformas económicas: El Derecho Penal”, Opinión A2, (consultado el 26.08.2013). Disponible en: http://www.colegioabogados.cl/cgibin/procesa.pl?plantilla $=/$ cont actividades detalle.html\&idart $=526 \&$ idcat $=140 \&$ nseccion $=$ activida des $+\mathrm{y}+$ noticias $+\% 3 \mathrm{~A}+\mathrm{Las}+$ otras + reformas + econ $\% \mathrm{~F} 3$ micas $\% 3 \mathrm{~A}+\mathrm{el}+$ derecho + penal + por + Gonz alo+Medina + Schulz

* MELO, Fabiola (2013): “Fiscal de caso lucro: hay 'bastante avance' en investigación por posibles fraudes al fisco" (consultado el 13.09.2013). Disponible en:

http://www.latercera.com/noticia/educacion/2013/08/657-539979-9-fiscal-de-caso-lucro-hay-

bastante-avance-en-investigacion-por-posibles-fraudes.shtml

* MUÑOZ, José y FERNÁNDEZ, José Ángel (2010): "Estudio dogmático penal de los artículos 291 del Código penal y 136 de la Ley General de Pesca y Acuicultura. A propósito del caso del Santuario de la Naturaleza Carlos Anwandter”, Polit. crim. (Vol. 5, No 10), pp. 410 - 454.

* ORTIZ, Verónica (2013): “Ceresita: Cuando salpica la pintura”, (consultado el 16.09.2013). Disponible en http://www.capital.cl/poder/ceresita-cuando-salpica-la-pintura/

* OSSANDON, María Magdalena (2003): "Eficiencia del Derecho penal. El caso de los delitos contra el medio ambiente", Revista de Derecho (XXIV, Valparaíso), pp. 379-394.

* OVALLE, Germán (2004): "El delito contra el medioambiente y delito de daños en el Código Penal Español. La relación concursal entre un delito de peligro abstracto con verificación de resultado", Revista Chilena de Derecho (Vol. 31 N $^{\circ}$ ), pp. 105-113.

* PALACIOS, Juan Pablo (2010): "PS denuncia: Dirección del Trabajo conocía desde julio riesgos de mina San José y no la cerró”, (consultado el 13.09.2013). Disponible en: http://radio.uchile.cl/2010/08/16/denuncian-que-mina-san-jose-debio-cerrar-en-julio

* PIETH, Mark (2011). "Die Weltweite Compliance-Revolution", en Weidenfeld, Ursula (Ed.), Nützliche Anwendungen? Der Fall Siemens und die Lehren für das Unternehmen, die Industrie und Gesellschaft (ed. Piper, München), pp. 75-84.

* PODERJUDICIAL.CL (2009): “Juzgado de Garantía de San Bernardo rechaza juicio abreviado en caso ADN”, (consultado el 02.09.2013). Disponible en: http://poderjudicial.cl/modulos/Home/Noticias/PRE noticias.php?cod=1894\&opc menu=\&op c item

(2013): "Corte de Santiago condena a Aguas Andinas por emanaciones de planta de tratamiento La Farfana”, (consultado el 13.09.2013). Disponible en: http://poderjudicial.cl/modulos/Home/Noticias/PRE noticias.php?cod=5561\&opc menu=\&op c item $=$ 
(2011): “2 Juzgado De Garantía Ordena Prisión Preventiva Para Ex Ejecutivos De La Polar” (consultado el 16.09.2013). Disponible en: http://www.poderjudicial.cl/modulos/Home/Noticias/PRE noticias.php?cod=3523\&opc menu $=0 \&$ opc menu=\&opc item $=$

* PUPPE, Ingeborg (2006): Die Erfolgszurechnung im Strafrecht (Nomos, Baden-Baden).

* ROSENBLUT, Verónica (2011): “El denominado caso 'Schwager': Análisis de histórica condena por uso de información privilegiada y manipulación bursátil”, Revista Jurídica del Ministerio Público $\mathbf{N}^{\circ}$ 46), pp. 185-209.

* ROTSCH, Thomas (2012): “Compliance”, en Achebach, Hans y Ransiek, Andreas, Handbuch Wirtschaftsstrafrecbt, (3a Ed., C.F. Müller, Müller, Heidelberg-München-Lendsberg-Hamburg), pp. 4575.

(2008) : “Criminal Compliance", (InDret 1).

(1998): Individuelle Haftung in Großunternehmen (Ed. Nomos, Baden-Baden).

ROXIN, Claus (2006): Strafrecht AT, T. i, (4ª ed., C.H. Beck, München).

* SCHÜNEMANN, Bernd (2002): "Responsabilidad penal en el marco de la empresa. Dificultades relativas a la individualización de la imputación”, (ADPCP LV).

(1979): Unternebmneskriminalität und Strafrecht (Carl Heynemanns, Köln-Berlin-Bonn-München).

* SUTHERLAND, Edwin H. (1940): "White-Collar Criminality”, American Sociological Review, (Vol. 5, $\mathrm{N}^{\circ}$ 1), pp. 1-12.

* TERrA (2005): "Cronología caso Celco", (consultada el 13.09.2013). Disponible en: http://economia.terra.cl/noticias/noticia.aspx?idNoticia=200506070522 INV 28549365,

* TOMBS, Steve (2008): “Corporation and Health and Safety”, en Minkes, John y Minkes, Leonard, Corporate and White-Collar Crime (Sage, Los Angeles-London-New Delhi-Singapore).

* TORRES, Verónica, GUZMÁN, Juan Andrés y RIQUELME, Gregorio (2011): “Cómo lucran las universidades que por ley no deben lucrar", (consultado el 13.09.2013). Disponible en: http://ciperchile.cl/2011/08/19/como-lucran-las-universidades-que-por-ley-no-deben-lucrar/

* ULLOA, Gabriela (2012): "Juez dicta acusación contra 22 personas en principal arista de Caso Inverlink”, (consultado el 06.12.2013). Disponible en: http://www.biobiochile.cl/2012/01/04/juezdicta-acusacion-contra-22-personas-en-principal-arista-de-caso-inverlink.shtml

* VALENZUELA, Jonatan (2013): “¿Por qué los pobres? Cárcel y dinero de cara al debate político chileno”, (consultado el 28.08.2013). Disponible en: http://www.redseca.cl/?p=4067,

* VEGA, Fernando (2013): “La Sheriff”, (consultado el 13.09.2013). Disponible en: http://www.capital.cl/poder/la-sheriff/

* VILLALOBOS, Gabriela (2011): “Solari y Zarour donarán \$15 millones para cerrar caso D\&SFalabella", (Consultado el 26.08.2013). Disponible en: http://www.economiaynegocios.cl/noticias/noticias.asp?id=84047

* VIVANCO, Nicolás (2013): “Caso Farmacias: Justicia aprueba suspensión condicional por un año a imputados”, (consultado el 02.09.2013). Disponible en:

http://www.latercera.com/noticia/negocios/2013/07/655-531986-9-caso-farmacias-justiciaaprueba-suspension-condicional-a-imputados.shtml

* WINTER, Gonzalo y SANHUEZA, José Miguel (2013): "Nuevo marco regulatorio de la Educación Superior: el caballo de Troya del lucro" (consultado el 26.08.2013). Disponible en: http://ciperchile.cl/2013/04/10/nuevo-marco-regulatorio-de-la-educacion-superior-el-caballo-detroya-del-lucro/

* WINTER, Jaime (2013): “Caso ADN y la causalidad en la responsabilidad por el producto", Revista Chilena de Derecho y Ciencias Penales (vol. II n 1), pp. 346-348.

* WITTIG, Petra (2011): Wirtschaftsstrafrecht (2a ed., C.H. Beck, München). 